\title{
Review Article \\ Herbal Medicine and Acupuncture for Breast Cancer Palliative Care and Adjuvant Therapy
}

\author{
Guo-Shiou Liao, ${ }^{1}$ Maria Karmella Apaya, ${ }^{2}$ and Lie-Fen Shyur ${ }^{2,3}$ \\ ${ }^{1}$ Tri-Service General Hospital, National Defense Medical Center, Taipei 114, Taiwan \\ ${ }^{2}$ Agricultural Biotechnology Research Center, Academia Sinica, No. 128, Section 2, Academia Road, Nankang, Taipei 115, Taiwan \\ ${ }^{3}$ Graduate Institute of Pharmacognosy, Taipei Medical University, Taipei 110, Taiwan
}

Correspondence should be addressed to Lie-Fen Shyur; lfshyur@ccvax.sinica.edu.tw

Received 21 March 2013; Revised 14 May 2013; Accepted 21 May 2013

Academic Editor: Yoshiharu Motoo

Copyright (C) 2013 Guo-Shiou Liao et al. This is an open access article distributed under the Creative Commons Attribution License, which permits unrestricted use, distribution, and reproduction in any medium, provided the original work is properly cited.

\begin{abstract}
Breast cancer is a life-threatening disease among women worldwide with annual rates of reported incidence and death increasing alarmingly. Chemotherapy is a recommended and effective treatment option for breast cancer; however, the narrow therapeutic indices and varied side effects of currently approved drugs present major hurdles in increasing its effectiveness. An increasing number of literature evidence indicate that complementary and alternative medicine (CAM) used in treatment-related symptom control and alleviation of side effects plays an important role in increasing survival rate and quality of life in breast cancer patients. This review focuses on the use of herbal medicines and acupuncture in palliative care and as adjuvants in the treatment of breast cancer. Herbal medicinal treatments, the correlation of clinical use with demonstrated in vitro and in vivo mechanisms of action, and the use of certain acupoints in acupuncture are summarized. The aim of this review is to facilitate an understanding of the current practice and usefulness of herbal medicine and acupuncture as adjuvants in breast cancer therapy.
\end{abstract}

\section{Introduction}

Breast cancer remains to be the leading cause of cancer death among women worldwide with the rate of reported incidence and mortality increasing annually $[1,2]$. In the past decade, women with tumors between stages I and II increased from $41 \%$ to $65 \%, 80 \%$ of which are invasive tumors originating from ductal carcinoma and its variants [3]. Current early detection methods allow breast cancer to be diagnosed at an early stage when successful treatment is more likely. Multiple agencies and organizations around the world support mammography as the most reliable way to detect breast cancer at an early stage, particularly in women aged 50 years and older $[4,5]$. About $70 \%$ of breast cancers express estrogen hormone receptor (ER) and/or progesterone receptor (PR), and these markers along with human epidermal growth factor receptor 2 (HER-2) and proliferation marker Ki-67 provide information about tumor grade and possible response to different treatments [6]. Although several treatment options are currently available including surgery, radiation therapy, and chemotherapy, specific treatment strategies depend on characteristics such as tumor grade, hormone receptor status, metastatic potential, and molecular and patient profile [7]. Chemotherapy is still the most commonly used and recommended treatment option for breast cancer, either by using a single compound or combination therapy with multiple drugs [8]. However, chemotherapeutic drugs have narrow therapeutic indices resulting in nonselective toxic effects on normal tissues, thus increasing the risk of infection. Although chemotherapy and radiotherapy are effective against breast cancer, they are accompanied by varied side effects including vasomotor syndrome (occurring in up to $80 \%$ of patients), nausea and vomiting (75\%), postmastectomy edema (30$60 \%$ ), arthralgia (over $40 \%$ ), neutropenia, cachexia, fatigue, pain, hair loss, hot flushes, and psychological stress, which present major hurdles in increasing the effectiveness of cancer therapy [7-10].

Palliative care is an important aspect of cancer therapy that centers on the relief of pain and other symptoms related to cancer and its treatment. It aims to improve the 
patient's quality of life (QOL) and can be administered along with curative treatment. Pharmacological interventions that reduce or prevent adverse side effects and increase chemosensitivity may have a substantial impact on cancer treatment and palliative care. Though the use of complementary and alternative medicine (CAM) by cancer patients is not part of conventional cancer palliative care regimens in some countries, according to the World Health Organization (WHO), $80 \%$ of cancer patients use CAM, in one form or another, for these purposes [11]. According to the WHO definition, the term CAM is used interchangeably with "traditional medicine" and refers to a broad set of health care practices, including traditional Chinese medicine (TCM), acupuncture, herbal preparations, vitamins, homeopathic remedies, music therapy, and other psychological, physical, and spiritual techniques [12-14]. The effectiveness of CAM is primarily based on empirical evidence and case studies however, in the recent years, the increasing amount of supporting data from controlled clinical trials relating CAM use to overall quality of life and safety has dramatically increased [15-17]. These supportive measures are supposed to control symptoms, improve QOL, boost the immune system, decrease cytotoxicity to normal cells, and possibly prolong life [17-20]. It may also be important to note that the integration of CAM into palliative care and cancer treatment regimens is influenced by culture [21]. One multicenter study that reported oncology professionals' attitude towards CAM concluded that in European countries, for example, CAM therapies commonly include mistletoe extracts, vitamin supplementation, and phytoestrogens, and only an approximately $4 \%$ of Scandinavian health practitioners, in contrast to the $20 \%$ German doctors, believe that CAM use has a positive role in adjuvant treatment of cancer patients [22]. Traditional oriental medicine systems (Chinese, Japanese, Korean, or Ayurvedic), spiritualism, hypnosis, aromatherapy, and acupuncture represent the widespread use of these CAM practices in the region [23]. In particular, China, Japan, Republic of Korea, and Taiwan operate a two-tiered medical system of integrative medicine, and CAM is fully integrated into national health, education, and insurance policies $[16,24,25]$. On the other hand, though not integrated in current oncological practice, $16 \%$ to $63 \%$ of North American cancer patients are reported to commonly use acupuncture, hypnosis, and spiritualism, as well as vitamin therapies and botanicals. In one population survey, $75 \%$ agreed that combining conventional medical treatment and CAM was preferable to using either alone $[26,27]$. The apparent widespread use of CAM worldwide and its (erroneous or otherwise) association with minimal or zero risk means that there is a significant need to do further studies to gain an understanding of the pharmacodynamic interactions between chemotherapeutic drugs and herbal components and the effects of either component and dosing regimens in cancer treatment and palliative care $[28,29]$.

Among cancer patients, CAM is used more frequently by breast cancer patients with an estimated use by $45 \%$ of patients across different treatment stages [30, 31]. In one survey done among long-term breast cancer survivors (on average, 8.7 years after-diagnosis), more than $50 \%$ believed that CAM use could prevent cancer recurrence (69\%), play an active role in recovery (67\%), and help to manage stress (64\%) [32]. Evidence gathered from recent randomized control trials (RCTs) demonstrates that herbal medicines and chemopreventive phytochemicals in combination with chemotherapeutic agents are effective in sensitizing cancer cells to treatment and minimizing the side effects arising from conventional therapy, thus increasing patient survival rate and QOL [18, 33-40]. In addition to herbal medicine, acupuncture has also become a popular complementary treatment in oncology, particularly as patients seek nonpharmacological alternatives to provide symptom control. A review of recent RCTs of acupuncture in oncology suggests that it has a promising role in controlling a wide variety of cancer and treatment-related symptoms. The evidence currently available suggests that acupuncture is a safe, low cost, and effective therapy, which further permits cancer patients to actively participate in their own care plan [41].

Several reviews had been done in the past on the use of either herbal medicine or acupuncture [42-47]; however, a comprehensive review of clinical trials utilizing either of these CAM methods in palliative care of breast cancer patients had not been done yet. This review focuses on the use of herbal medicine treatments, either as single herbs or combinations, and acupuncture in palliative care and as adjuvants in combination with chemo- or radiotherapy in the treatment of breast cancer based on recently conducted or completed RCTs. The correlation between clinical use, in vitro mechanistic and in vivo animal studies of herbal medicine, and the effectiveness of acupuncture with the use of certain acupoints in breast cancer patients is summarized and is aimed at facilitating an understanding of current practices involving the use of herbal medicine and acupuncture as adjuvants in breast cancer therapy.

\section{Methods}

An electronic search for previously published articles was conducted in PubMed, the Cochrane Database, the US National Center for Complementary and Alternative Medicine (NCCAM) (http://www.nccam.nih.gov/), and the US National Institutes of Health (http://www.clinicaltrials .gov/) databases to find relevant studies published up until February 2013 (inclusive). The search included the following specific medical subject heading (MeSH) terms: breast cancer, AND/OR breast neoplasms, AND/OR adjuvant chemo/radiotherapies, AND/OR herbal medicine, AND/OR acupuncture, AND/OR acupuncture points in addition to relevant text keywords comprising the following words in combination: cancer palliative care, traditional Chinese medicine, herbal formulation, phytoagent, and acupoints. The article or study types were limited to clinical trials (Phases I to IV), controlled clinical trials, and randomized controlled trials (RCTs). The titles and abstracts of all retrieved citations were read and analyzed. In total, 90 RCTs, either completed or ongoing, were included regardless of blinding. The most common phytoagents, single herbal treatments, herbal formulations, and acupoints used in the retrieved RCTs were singled out. Moreover, an exhaustive 
search for references regarding in vivo and in vitro studies pertaining to mechanistic actions, acupuncture practices, individual acupoints, treatment-related symptoms, and associated effects was conducted.

Furthermore, the herbal medicine and acupuncture practices included in the most recent RCTs are highlighted in this review because these are generally accepted as constituting the most reliable evidence of treatment effects $[48,49]$. RCTs include experiments wherein individuals are randomly allocated to receive or not receive experimental preventive, therapeutic, or diagnostic procedure; they are then followed over a given time period to determine the effects. The RCTs included in this review were either completed or ongoing and are assumed to have complied with health and ethics regulations in the countries where they were conducted. In the following sections, we summarize and describe the results and discuss in some detail the related mechanisms of action and therapeutic effects of these CAM practices as applied in the adjuvant treatment and palliative care of breast cancer patients.

\section{Results and Discussion}

3.1. Herbal Medicines as Adjuvant Treatment in Breast Cancer Chemotherapy. The most common complaint among patients receiving chemotherapy treatment is fatigue, which is experienced by $80 \%$ to $96 \%$ of the patient population [50]. Chemotherapy-induced mucositis and myelosuppression, experienced by almost $40 \%$ of patients, are the common, dose-limiting, and costly side effects of cancer therapy [51]. Moreover, cytotoxic chemotherapy suppresses the hematopoietic system, impairing the immune system and limiting the doses of drugs that can be tolerated by the patient [52]. Table 1 summarizes the conventional/approved drugs used in breast cancer chemotherapy together with their major mechanisms of action and most commonly observed side effects [50-63]. Several drugs have been used in combination, for example, cisplatin-methotrexate fluorouracil (CMF), fluorouracil-epirubicin-cyclophosphamide (FEC), and FECtamoxifen (FEC-T), supposedly to increase efficacy and reduce side effects. Patients, however, still experience fatigue, phlebitis, alopecia, nausea, mucositis, anemia, and myelosuppression alongside long-term side effects including ovarian failure, weight gain, cardiac dysfunction, and, in some cases, leukemia $[64,65]$. Herbal medicines and natural supplements are widely used in cancer chemoprevention in the clinic and are also studied in vitro and in vivo $[66,67]$.

3.1.1. Traditional Chinese Medicines Composed of Multiple Herbs. In traditional medicinal systems, herbal medicines are used often to treat the symptoms associated with cancer and the side effects of cancer treatment [68]. Herbal formulations used in TCM include mixtures of herbal compounds constituted as decoctions, tea, injections, or capsules, which are purported to possess anticancer compounds and are used alone or as adjuvants to existing chemotherapy regimens to improve efficacy and/or reduce drug-induced toxicity [69]. Although TCM is commonly used to counteract the side effects of chemotherapy, scientific evidence for its use in women with breast cancer still is being collected. Among the most common Chinese medicinal herb formulations used in preclinical and clinical practice for breast cancer treatment are Danggui (Angelica sinensis-radix) and Ren Shen (Panax ginseng-radix), which are reported to have potential beneficial synergistic effects that include decreasing treatmentassociated toxicity, psychosocial stress, and fatigue [70]. Jia-wei-xiao-yao-san, commercially known as "Augmented Rambling Powder," a Chinese medicinal herb formulation containing Danggui, is the most frequently prescribed formula for treating breast cancer and chemotherapy-related symptoms by TCM practitioners in Taiwan. This formulation has a long history of use for alleviation of blood toxicity and sleep disturbance. It is also used to relieve hot flushes and lower serum levels of inflammatory cytokines, IL-6, IL-8, and macrophage protein 1- $\beta[71,72]$.

LSC101, an encapsulated homogenized mixture of dry powdered extracts from a combination of medicinal herbs, including Astragalus membranaceus, Poriae cocos, Atractylodes macrocephala, Lycium chinense, Ligustrum lucidum, Paeonia lactiflora, Paeonia obovata, Citrus reticulata, Ophiopogon japonicus, Millettia reticulata, Oldenlandia diffusa, Scutellaria barbata, Prunella vulgaris, and Glehnia littoralis, is used widely by breast cancer patients. Its efficacy in attenuating the hematological complications of chemotherapy has been tested in clinical settings [70]. In mouse breast cancer models, the use of LSC101 together with doxorubicin led to significantly higher neutrophil, splenic erythrocyte, and leukocyte counts [71]. In addition, the use of LCS101 together with conventional chemotherapy regimens provided protection against mild to moderate chemotherapyinduced anemia and neutropenia, supporting its use for decreasing hematological toxicity but not cancer prevention [73]. Though it is not yet clear how the compounds in LCS101 reduce hematological toxicity, it is suspected that the interactions and synergistic effects of the active compounds from the combination of herbs may be responsible for the pronounced efficacy [74]. Some of the component herbs, for example, Ophiopogon japonicus and Astragalus membranaceus, in LSC101 have been independently shown to stimulate the production of erythroid progenitor cells in mice and promote recovery of hematopoietic function in patients with chronic aplastic anemia [75]. A TCM formulation composed of five herbs, commonly known as "Ruyiping" and "Runing II," is used as treatment for detoxification and preventing relapse, recurrence, and metastasis in breast cancer patients after mastectomy [76]. Clinical evidence suggests that the mechanism of action of this herbal formulation is via inhibition of angiogenesis and downregulation of vascular endothelial growth factor (VEGF) and VEGF receptor as well as microvessel count (MVC) and micro-vessel area (MVA) $[75,76]$.

Shenqi Fuzheng Injection (SFI), a TCM formulation used in repairing immune function at the cellular and molecular levels, is also effective in alleviating myelosuppression and GI tract reaction induced by chemotherapy and surgical operation [77]. In clinical evaluations, the protein expressions 
TABLE 1: Summary of major mechanisms of action and common side effects of chemotherapeutic drugs approved for breast cancers.

\begin{tabular}{|c|c|c|c|}
\hline $\begin{array}{l}\text { Chemotherapeutic } \\
\text { agent }\end{array}$ & Mechanism of action & Side effect & References \\
\hline Cyclophosphamide & Apoptotic cell death & Pulmonary toxicities, weight gain & {$[50,52]$} \\
\hline Cisplatin & DNA damage, apoptosis & Nephrotoxicity & {$[54]$} \\
\hline Doxorubicin & DNA damage & Impaired cognitive function, anemia & {$[55,56]$} \\
\hline Docetaxel & Mitotic inhibition & Pulmonary toxicities, colitis, diarrhea & {$[57]$} \\
\hline Epirubicin & DNA damage & Nausea, cardiotoxicity & {$[58-60]$} \\
\hline Fluorouracil & $\begin{array}{l}\text { Thymidylate synthetase inhibition; DNA } \\
\text { synthesis inhibition }\end{array}$ & Cardiotoxicity, anemia, GI tract toxicity & {$[61]$} \\
\hline Gemcitabine & Nucleic acid synthesis inhibition & GI tract toxicity & {$[62]$} \\
\hline Methotrexate & Cell cycle arrest & $\begin{array}{l}\text { Anemia, weight gain, jaundice, diarrhea, loss of bone } \\
\text { density }\end{array}$ & {$[50]$} \\
\hline Mitomycin & DNA alkylating agent & Myelotoxicity, fatigue, systemic toxicity & {$[63]$} \\
\hline Mitoxantrone & Topoisomerase inhibition & Alopecia, systemic toxicity & {$[63]$} \\
\hline
\end{tabular}

of CD83, CD80, and CD86 in patients' tumor tissue and auxiliary lymph nodes were detected before and after treatment. Results suggest that SFI could help repair immunity impaired by cancer and cancer treatment by activating dendritic cells and upregulating costimulatory molecules $[77,78]$. Clinical studies using a natural dietary supplement composed of a combination of medicinal mushrooms Coriolus versicolor, Ganoderma lucidum, and Phellinus linteus and medicinal herbs Scutellaria barbata, Astragalus membranaceus, and Curcuma longa suggested that the formula can alleviate chemotherapy-induced toxicity in liver, spleen, kidney, lung, and heart tissue [79]. In vitro studies also elucidated the mechanism of action of this mushroom-herbal formulation in inhibiting proliferation and lowering the invasive behavior of a highly metastatic human cancer cell line, MDA-MB231, by the inhibition of cyclin A1 expression and by the downregulation of CXCR4 [79-81].

A combination of rose geranium (Pelargonium graveolens, Geraniaceae), Ganoderma tsugae (Ganodermataceae), Codonopsis pilosula (Campanulaceae), and Angelica sinensis (Apiaceae) (RG-CMH) has been used in TCM treatments for breast cancer and is associated with immunomodulation based on anti-inflammatory and wound-healing properties attributed to the synergistic activity of the components of the herbs [82]. In one RCT, RG-CHM intervention improved the immune cell count of cancer patients receiving chemotherapy and/or radiotherapy preventing leukopenia and immune impairment associated with a decrease in levels of $\mathrm{T}$ cells, helper T cells, cytotoxic T cells, and natural killer cells compared with the group receiving placebo treatment. However, the differences between the two groups were not statistically significant [83]. The results did show, however, that the administration of RG-CMH to patients receiving chemotherapy/radiotherapy delayed the reduction in levels of leucocytes and neutrophils experienced by patients undergoing cancer treatment $[83,84]$.

Yunzhi-Danshen (Coriolus versicolor and Salvia miltiorrhiza) capsules have been shown to benefit the circulatory system through vasodilation, immunomodulation, and antidementia activities [85]. Results of a recent RCT showed that the absolute counts of T-helper lymphocytes (CD4+), the ratio of T-helper $(\mathrm{CD} 4+) / \mathrm{T}$ suppressor and cytotoxic lymphocytes (CD8+), and the percentage and the absolute counts of B lymphocytes were significantly elevated in patients after taking Yunzhi-Danshen capsules. These clinical findings imply that regular oral consumption of Yunzhi-Danshen capsules could be beneficial for promoting immunological function in breast cancer patients after chemotherapy [85, 86]. These findings were also supported by in vitro results showing that Yunzhi-Danshen treatment inhibited cancer cell proliferation by cell-cycle arrest and downregulation of Akt phosphorylation in MCF7 cells, a human breast cancer cell line, and by inducing apoptosis $[87,88]$.

3.1.2. Single Herbs and Medicinal Mushrooms. Black cohosh (Cimicifuga racemosa) is known in TCM to reduce hot flushes in menopausal women and to have low toxicity. Several clinical studies have backed up this claim [89-92]. Since breast cancer chemotherapeutics such as cytostatics, aromatase inhibitors, or antiestrogens frequently induce or aggravate preexisting menopausal symptoms, extracts of $C$. racemosa are currently being explored as an adjuvant. The mechanisms of action of this phytotherapeutic herb are still not totally understood, but there is growing interest in its usefulness in the treatment of vasomotor symptoms and hot flushes and in preventing the decrease in bone density associated with menopause $[93,94]$. The use of black cohosh in clinical trials as an adjuvant to chemotherapy was observed to help patients improve their QOL through relief of vasomotor symptoms $[95,96]$. Moreover, in vitro studies using MCF7 cells showed the high antitumor activity of C. racemosa extracts and their involvement in induction of apoptosis [97].

Coriolus versicolor (Yunzhi) also known as Trametes versicolor is a popular component in TCM mushroom preparations. Several clinical trials with patients receiving chemotherapy or radiotherapy have found that encapsulated Yunzhi preparations significantly improve appetite, alleviate weakness, anorexia, vomiting, dryness of the throat, and 
spontaneous or night sweats and pain, increase weight, stabilize white blood cell counts, NK cells, IL-2 levels, and CD4/CD8 ratio, and demonstrate a 9\% absolute reduction in 5-year mortality rate [98-100]. Polysaccharide-K (PSK), also known as krestin, is one of the active compounds found in Yunzhi [83]. It is a unique protein-bound polysaccharide, which has been used as a chemoimmunotherapy agent. Several RCTs have demonstrated the efficacy of PSK as an adjuvant in cancer therapy, with positive results seen in the adjuvant treatment of gastric, esophageal, colorectal, breast, and lung cancers. PSK is a biological response modifier (BRM) that improves the ability of cancer patients to fight off tumor progression through different mechanisms, most probably by leukocyte activation, regulation of IFN- $\gamma$ and IL-2 levels, and inhibition of metalloproteinases and other enzymes involved in metastatic activity [101-105]. PSK has further been shown to have antioxidant activity which may allow it to play a role as a normal tissue chemo- and radioprotector when used in combination with adjuvant or definitive chemotherapy and/or radiotherapy in the treatment of cancers and may also enable it to defend the host from oxidative stress [106].

Ganoderma Lucidum, also known as Lingzhi, is used in TCM to promote health and increase life expectancy [137]. Clinically, the spore powder is used to treat cancer-related fatigue in breast cancer patients undergoing endocrine therapy. Patients given the treatment reported improved physical well-being, less fatigue, less anxiety and depression, and overall better QOL. Comparative evaluation of TNF- $\alpha$, IL6 , and liver and kidney function before and after interventions showed a statistically significant effect [138]. The wide spectrum of biological effects reported for G. lucidum in the prevention of chronic diseases, such as hepatitis, hepatopathy, and hypertension, makes it a viable adjuvant for hepatoprotection in cancer therapy [139]. Among the active compounds present in G. lucidum extracts, triterpenoids are one of the main components responsible for the pharmacological activities including immunomodulatory, antioxidative, antimetastatic, and antitumor effects [140]. In vitro and in vivo assays have revealed that the mixtures of triterpenoids in G. lucidum exerted antiproliferative effects by inducing apoptosis and cell-cycle arrest [141].

Ginseng (Panax Ginseng) is one of the most well-known herbal remedies and is used in TCM to proactively promote health, vitality, and longevity. Ginseng is ranked as the fourth top-selling herbal medicine globally $[142,143]$. In recent years, ginseng has been included in the pharmacopoeias of Germany, Austria, the United Kingdom, and the United States. In adjuvant breast cancer therapy, ginseng has been used to maintain natural energy, increase physical and psychomotor performance, and improve mood and general health $[144,145]$. In vitro experiments and in vivo animal studies have reported that ginsenosides, a group of bioactive compounds identified in ginseng, have a variety of beneficial effects, including immunomodulatory, antistress, antifatigue, and anticarcinogenic effects [146].

Accumulating evidence from epidemiologic, clinical, and laboratory studies has revealed an inverse-relationship between increased intake of green tea (Camellia sinensis) and relative risk for breast cancer [147]. Green tea extract polyphenon $\mathrm{E}$ (PPE) containing bioactive compound epigallocatechin gallate (EGCG) was supplemented as decaffeinated green tea capsules for 2 months in a double-blind, randomized, and placebo-controlled intervention study. Results suggest the beneficial effects of EGCG on LDL-cholesterol concentrations and glucose-related markers [148]. Since green tea has been associated with weight control and cardiovascular disease prevention, its effect on weight gain after breast cancer treatment was also investigated [149]. A slight reduction in body weight and improved HDL and glucose homeostasis was seen in overweight breast cancer survivors. These clinical findings, together with substantial in vitro and in vivo evidence, suggest that tea polyphenols can be used as chemopreventive agents and as adjuvant treatments for breast cancer [149-151].

Mistletoe (Viscum album) extracts have been used for cancer therapy since the early 1920s, most commonly in central Europe [152, 153]. Most recent clinical studies have focused on the use of mistletoe extracts as adjuvants for chemotherapy specifically for nausea/vomiting and the side effects of systemic therapy [154]. The active compounds in mistletoe treatment are the recently identified mistletoe lectins (ML I, II, and III) that consist of two polypeptide chains: a carbohydrate-binding $B$ chain that can bind to cell surface receptors enabling the protein to enter the cell, and the catalytic A chain, which can subsequently inhibit protein synthesis, due to its ribosome-inactivating properties [155, 156]. Other pharmacologically relevant compounds found in mistletoe are viscotoxins and other low molecular proteins, oligo- and polysaccharides, flavonoids, and triterpene acids, which have been found to act synergistically resulting in the cytotoxic and apoptosis-inducing effects of the whole plant extract $[157,158]$. One RCT showed that mistletoe preparations boosted the immune system in low doses, helping to improve the QOL and survival of some cancer patients by as much as $40 \%$ alongside cotreatment with chemo- and radiotherapy. These results are attributed to the overregulation of genes responsible for immune defense, stress response, apoptosis, and cell-cell adhesion pathways [159-162].

Rhodiola algida is widely used in TCM to stimulate the immune system. Oral ulcerative mucositis, a common adverse effect of mainstream cytotoxic drugs, limits the nutritional intake of cancer patients. One clinical study demonstrated the effects of $R$. algida in alleviation of the occurrence of oral ulcers after four cycles of chemotherapy using 5-fluorouracil, epirubicin and cyclophosphamide, and postmasectomy [163]. Lymphocyte proliferation was induced and serum levels of IL-2, IL-4, and granulocyte-macrophage colony-stimulating factor (GMC-SF) were increased by taking $R$. algida extracts. While white blood cell (WBC) levels returned to the normal range a week after every cycle of chemotherapy, WBC count increased faster in patients using R. algida. Patients also presented fewer and smaller oral ulcers and no liver or renal complications were observed in any of the patients involved in the study. Thus $R$. algida has the potential to be used concurrently with chemotherapy to alleviate the occurrence of oral ulcers [163-165]. 
Several flavonoids with cytotoxic activity have been isolated from the aqueous extract of the aerial part of Scutellaria barbata. Despite identification of several active chemical compounds, none demonstrated more potent cytotoxic activity than the whole plant extract. Thus, the whole herb extract is being used and studied clinically [166168]. In one multicenter, open-label, and dose-escalation phase 1B clinical trial, S. barbata extract was administered orally, once or twice daily on a continuous basis to women with advanced metastatic breast cancer (MBC) receiving chemotherapy. Dose-limiting side effects were decreased including aspartate transferase (AST) elevation, diarrhea, fatigue, and pain, proving this herb to be effective and safe and thus showing promise in the treatment of side effects related to the treatment of women with MBC [169]. Most notably, the components of the whole herb extract work in synergy to inhibit cell proliferation, induce cell-cycle arrest, stimulate ROS production and hyperactivation of poly(ADPribose) polymerase(PARP), and inhibit glycolysis [170].

Curcumin, the principal active component of turmeric (Curcuma longa), has potential therapeutic activities against breast cancer through multiple signaling pathways [171]. It has been widely reported to reverse chemoresistance and sensitize cancer cells to chemotherapy and targeted therapy in breast cancer [172, 173]. In cell models, curcumin could suppress expression of progrowth and antiapoptosis molecules, induce inactivation of NF- $\kappa \mathrm{B}$, Src, and Akt/mTOR pathways, and downregulate the key epigenetic modifier EZH2 [174178]. One clinical study reported that when curcumin was used as an adjuvant with docetaxel, dose-limiting toxicity effects were significantly decreased [175].

Uncaria tomentosa, commonly known as Utor Cat's Claw, is a medicinal herb used in the treatment of different diseases including cancer, arthritis, gout, and epidemic diseases [179]. Whole plant extracts were reported to have cytostatic and anti-inflammatory activity, and patients who use Cat's Claw along with chemotherapy and radiation report fewer adverse effects [180]. The use of $U$. tomentosa helps in the restoration of cellular DNA, preventing mutations and cell damage caused by chemotherapy drugs [181]. In addition to its antioxidant properties, $U$. tomentosa modulates the activity of the immune system by proliferation of normal $\mathrm{T}$ and $\mathrm{B}$ lymphocytes and modulation of certain cytokines, including IL-1, IL-6, and TNF- $\alpha$ [182-184].

\subsection{Use of Acupuncture in Breast Cancer}

3.2.1. Definition and Concept of Acupuncture. The National Institutes of Health (NIH), USA, has defined acupuncture as a family of procedures involving stimulation of anatomical locations on the skin by a variety of techniques. The most studied mechanism of stimulation of acupuncture points uses penetration of the skin by thin, solid, and metallic needles, which are manipulated manually or by electrical stimulation [185].

The general theory of acupuncture is based on the premise that bodily functions are regulated by an energy called "qi" which flows through the body; disruptions of this flow may cause disease [186]. Traditional acupuncturists understand qi as circulating between the organs along channels called meridians, which are classified as yin or yang meridians [187]. Yin meridians include the lung, spleen, heart, kidney, pericardium, and liver, while yang meridians include the stomach, large intestines, small intestines, bladder, triple energizer, and gall bladder [188, 189]. Qi energy must flow in the correct strength and quality through each of these meridians and organs for health to be maintained. Throughout the history of Chinese medicine and descriptions in Huangdi Neijing, the concept of balancing yin and yang had been extensively applied in the application of combination of meridians, corresponding organs, and acupuncture points or acupoints $[188,189]$. Acupoints are mainly (but not always) found at specific locations along the meridians which provide one means of altering the flow of qi. There are also a number of acupuncture points with specified locations outside the meridians; these are called "extraordinary" points and are often credited with special therapeutic properties. A third category of acupuncture points called "A-shi" points have no fixed location but represent tender or reflexive points appearing in the course of pain syndromes [188]. Acupuncture points are thought to correspond to conventional (Western) physiological and anatomical features, such as the peripheral nerve junctions, and are known to stimulate the release of neurotransmitters, partially explaining its effect particularly in pain management [189].

3.2.2. Scientific Exploration into Acupuncture. Acupuncture is aimed at correcting imbalances in the flow of qi by stimulation of acupoints by a variety of techniques which involves the insertion of fine needles into the skin and underlying tissues at specific points, for therapeutic or preventative purposes. Evidence of the neurophysiological mechanisms underlying acupuncture now exists [190-193]. For example, the release of a number of endogenous substances including $\beta$-endorphin, met-enkephalin, and dynorphins was observed during treatment [194-196]. Moreover, acupuncture can alter gene expression, upregulating opioid production [197, 198]. Acupuncture works by modulating noradrenergic and serotonergic pathways to give extra segmental pain relief, that is, analgesia throughout the body [199]. Acupuncture releases serotonin [200], oxytocin [201], and endogenous steroids [202], which may further contribute to analgesia. In functional MRI studies, acupuncture induced brain activation in the hypothalamus and nucleus accumbens and deactivated areas of the anterior cingulate cortex, amygdala, and hippocampus. In terms of analgesia, it was suggested that acupuncture modulated the affective-cognitive aspect of pain perception [199]. Furthermore, correlations between signal intensities and analgesic effects have been reported [203]. Further work using PET scanning showed that acupuncture induced extra effects in the ipsilateral insula beyond the sham needle, which also had greater effects on activation patterns than the control group [107].

Recent advances in clinical research on acupuncture suggest that acupuncture provides clinical benefit for breast oncology patients in symptom control and supportive care. 
Symptoms that respond to acupuncture treatment include pain, gastrointestinal side effects, hot flushes, fatigue, anxiety, depression, and insomnia. Patients welcome a supportive therapy that can reduce symptoms without the need for longterm medication. The strength of current scientific evidence has made acupuncture more acceptable to Western-trained doctors and given rise to Western medical acupuncture [108].

\subsection{Effectiveness of Acupuncture in Breast Cancer Patients and Suggested Acupoints}

3.3.1. Cancer-Related Hot Flushes. Twelve trials explored the effect of acupuncture on vasomotor syndrome (summarized in Table 2) [109-116, 204, 205], including eight RCTs and four single-group pre-post comparisons. Daily flush frequency was the main outcome measure. All the studies used selfadministrated questionnaires to measure this effect. Some trials also used the Kupperman Index (KI) to score climacteric symptoms. Most studies used six or more acupoints of which SP6 was the most commonly used. A course of acupuncture treatment has been found to reduce hot flushes associated with normal menopause and also from hormonal treatments for cancer. Studies found that acupuncture reduced hot flushes by up to $60 \%$ in women treated with tamoxifen for breast cancer [108, 110, 111, 205]. Those in the acupuncture group additionally reported improved libido, increased energy, and improved clarity of thought and sense of well-being. Furthermore, the acupuncture group reported no adverse side effects. An algorithm has been developed for the long-term treatment of hot flushes, with the observed effects of the initial course of treatment maintained for up to 6 years by weekly self-needling at SP6 or by using semipermanent needles [117]. For self-needling, patients require clear demonstration of cleansing, insertion, and safe disposal [118].

3.3.2. Nausea and Vomiting. Ten studies included in Table 2 investigated the antiemetic effect of acupuncture on distress symptoms induced by chemotherapy [119-126]. Participants received intervention over a treatment period of 5 days to 3 weeks. These studies, including three high quality studies $[118,119,121]$, reported that acupuncture could significantly improve emesis caused by breast cancer therapy. Acupuncture stimulation at points PC6 and ST36 has repeatedly been shown to be a clinically useful antiemetic treatment for postoperative nausea and vomiting and chemotherapyinduced emesis. In 1998, the US NIH stated that "acupuncture is a proven effective treatment modality for nausea and vomiting" [185]. A three-arm RCT comparing conventional antiemetics alone with antiemetics plus either electroacupuncture or minimal acupuncture demonstrated that the electroacupuncture plus antiemetics arm was the most effective for preventing nausea and vomiting associated with high-dose chemotherapy [121]. Ezzo and colleagues reviewed eleven trials in 2006 and concluded that electroacupuncture has demonstrated benefit for chemotherapy-induced acute vomiting, and self-administered acupressure appears to have a protective effect against acute nausea and can readily be taught to patients [206]. Since then, two multicenter longitudinal RCTs have shown the beneficial effect of acupressure in significantly reducing the severity of both acute and delayed vomiting $[118,119]$. These studies also demonstrate that acupuncture and acupressure are simple to administer and merit wider consideration.

3.3.3. Pain. Up to $70 \%$ of cancer patients still suffer significant pain which adversely impacts their QOL [207]. Bone pain is the most common type of cancer-associated pain, and bone metastases are common in advanced breast cancers. Current pain-relieving strategies include the use of opioidbased analgesics, bisphosphonates, and radiotherapy. The pharmacological failure to control pain alone has led to the use of nondrug treatments including acupuncture. The analgesic effects of acupuncture may permit a decrease in the requirement and side effects of pharmaceuticals. It can also help those who are sensitive to normal doses of analgesics and those who have pain despite analgesic dose titration [196]. Although acupuncture is used in palliative care settings for all types of cancer pain, the evidence base is still insufficient and inconclusive and there is very little evidence to show its effectiveness in relieving cancer-induced pain [208, 209].

Three trials used acupuncture to manage postmastectomy pain (Table 2) [127-129, 208, 209]. Acupoint L14 was used in all the three trials. Two studies demonstrated a significant effect favoring the acupuncture group $[128,129]$, but one high quality RCT [127] found no significant difference between the intervention group and the control group. Although reviews vary in their conclusions, acupuncture was found to be superior to no treatment or waiting list control in most studies.

Finally, emerging evidence demonstrates the analgesic effectiveness of both acupuncture and electroacupuncture in breast cancer patients experiencing joint pain as a result of adjuvant aromatase inhibitor treatment. Four trials have included investigation of arthralgia, and all explored the effect of acupuncture therapy on aromatase inhibitor-related joint pain and functional ability (Table 2). Positive results were obtained including enhanced postoperative analgesic efficiency, relief of postoperative pain, and significant improvement in joint and muscle stiffness [128, 130-132, 210].

3.3.4. Fatigue. Fatigue is an extremely common symptom in cancer patients [211]. Fatigue is also an adverse side effect of chemotherapy and radiotherapy, which can persist long after the cessation of treatment. In a prospective phase II study on patients with persistent fatigue who had previously completed chemotherapy, acupuncture resulted in a significant reduction in baseline fatigue scores [212]. Further four RCTs showed that acupuncture was associated with a significant improvement in general fatigue scores [213-216].

3.3.5. Anxiety, Depression, and Insomnia. The two anxiety, sickness, and dyspnoea (ASAD) points located at the upper left and right sternal regions are used extensively in the UK to control dyspnea and also anxiety. Patients can massage 
TABLE 2: Summary of the effectiveness of acupuncture (acupoints) used in breast cancer patients for cancer-related syndromes or side effects caused by treatments.

\begin{tabular}{ll}
\hline Symptoms & Acupoints used \\
\hline & LIV3, GB20, LU7, KI3, SP6, REN4, P7, LIV8 \\
& DU14, GB20, BL13, PC7, H6, K7, ST36, SP6, \\
& Ear shen men, Ear sympathetic point, \\
& BL23, BL32, HT7, SP6, SP9, LR3, PC6, GV20 \\
& KI6, SP6, BL23, CV4, GB35, H5 \\
Hot flush & BL62, LR14, KI3, HT7, TE6, SP6, LI11, ST36, GV20, LI4 \\
& \\
& P6, ST36, LI4 \\
Nausea and vomiting & LI4, SP6, auricular points, \\
& GB6, SJ6, PC2, PC3, LE14, MP19, DI14, BL17, LU2, RE6, RE17 \\
Postmastectomy pain & TB5, GB41, GB34, LI4, ST41, KD3, LI15, SJ14, \\
& SI10, SJ4, LI5, SI5, SI3, LI3, Du3, Du8, UB23, \\
Arthralgia & GB30, GB39, SP9, SP10, ST34 \\
& CV2, CV3, CV12, LI15, TE14, LU5, TE5, LI4, \\
Lymphedema & ST36, ST6, SP9, SJ5, SJ14, REN2, REN3, REN12 \\
Leukopenia & ST36 \\
\hline
\end{tabular}

acupuncture studs for 1-2 min on demand to provide anxiolysis [196]. This method has the added benefit of empowering the patient to control these distressing symptoms in the event of a panic attack. In a systematic review of RCTs of acupuncture in the treatment of depression, Leo and Ligot Jr. stated that although the odd ratios derived from comparing acupuncture with control conditions in the existing literature suggest a role for acupuncture, the evidence is thus far inconclusive [217]. More recent evidence suggests that acupuncture when combined with antidepressant therapy has a faster therapeutic onset rate than pharmacotherapy alone, coupled with a reduction in the side effect profile of the antidepressant medication [218]. An additional RCT examining the treatment of hot flushes revealed that compared to women taking venlafaxine, those receiving acupuncture felt they had more energy, improved clarity of thought, increased libido, and a greater sense of well-being [219]. In one study done by Mehling and colleagues, massage and acupuncture in postoperative cancer patients who were also receiving usual care resulted in a significant improvement in their depressed mood with short-lived significant improvement in tension and anxiety when compared to patients receiving usual care alone [220]. A subsequent meta-analysis revealed that the rate of improvement in insomnia produced by auricular acupuncture was significantly higher than that achieved by taking Diazepam [221]. Although a Cochrane systematic review of acupuncture for insomnia in 2007 concluded that acupuncture or its variants were not more effective than the control groups [222], five clinical studies showed significant improvement in anxiety and depression over time in patients who underwent acupuncture treatment. QOL measures of pain severity and interference, physical and psychological distress, life satisfaction, and mood states also showed improved scores after acupuncture treatment [223227].

3.3.6. Lymphoedema and Leukopenia. Lymphoedema is a distressing problem that affects many women after breast cancer surgery. In the United States, needling and even lifting objects using the affected arm has been prohibited, resulting in a limited number of publications on acupuncture and lymphoedema [133]. However, recent results of two studies demonstrated that traditional acupuncture after breast cancer surgery was associated with improvements in movement amplitude of the shoulder, symptoms of heaviness and tightness in the arm, and the degree of lymphedema [133, 134].

Two trials conducted in China found that dexamethasone injected at the ST36 intra-acupoint was effective in preventing bone marrow suppression-related leukopenia in breast cancer patients undergoing chemotherapy or radiotherapy (Table 2) $[135,136]$. The main body of evidence comes from China where a systematic review of RCTs was positive for increasing WBC in patients undergoing chemotherapy [228]; however, the quality of trials was considered poor, and the authors suggest that the positive meta-analysis should be considered as exploratory.

3.4. Safety of Acupuncture. With an increasing number of positive evidence-based acupuncture trials, more cancer patients may seek acupuncture treatment. While closely monitored clinical trials often report low incidences of adverse events of acupuncture, many physicians remain concerned about its safety. Serious adverse events are exceedingly rare-roughly five in one million [229] — and are usually associated with poorly trained, unlicensed acupuncturists [230]. The vast majority of adverse events from acupuncture 
are minor; those most commonly reported occur at the site of needle insertion: minor bleeding (3\%), hematoma $(2-3 \%)$, and pain from needling (up to $3 \%$ ). Dizziness is reported in about $1 \%$ of treatments [229, 231, 232]. Serious adverse effects including pneumothorax, spinal lesions, and hepatitis $B$ transmission have been reported in the literature for acupuncture, but these are rare and are generally associated with poorly trained unlicensed acupuncturists [233]. Acupuncture for oncology should be administered by a suitably qualified practitioner who can maintain a constant dialogue with the oncology team treating the patient. The contraindications and cautions for acupuncture in an oncology setting are outlined in Table 3.

In general, acupuncture can be considered a safe method of treatment, with a low side effect profile, which in part adds to its popularity among patients [234-236]. Establishing an eligibility guideline for cancer patients before receiving acupuncture would add another layer of safety. Lu and Rosenthal suggested that cancer patients should not be recommended for acupuncture if they have one of the following conditions: (a) absolute neutrophil count (ANC) less than $500 / \mu \mathrm{L}$, (b) platelet count less than $25,000 / \mu \mathrm{L}$, (c) altered mental state, (d) clinically significant cardiac arrhythmias, and (e) other unstable medical conditions (case-by-case consideration). Guidelines for safe practice within this field have previously been published [237]. Before the first visit, approval is required from the primary oncologist based upon these guidelines [238].

\section{Conclusions and Future Prospects}

Research on CAM as adjuvants in chemotherapy and/or radiotherapy, particularly that on herbal medicine and acupuncture, has gained momentum over the past few years. This development paves the way toward understanding their efficacy and modes of action in alleviating cancer or cancer treatment-related conditions. Evidence from various in vitro, in vivo studies and RCTs support the use of herbal medicine or acupuncture in boosting the immune system, in relieving pain, fatigue, cyto- and hepatotoxicity, and in inhibiting gastrointestinal toxicity, angiogenesis, and other side effects from chemo- and radiotherapy. The inclusion of selected herbal medicines from well-designed RCTs in this review provides evidence-based knowledge to strengthen the rationale for the use of herbal medicines in controlling breast cancer in the clinical setting. Further, considering the assessment of benefit: risk ratio of the presented results, acupuncture is seen as a valuable nonpharmaceutical treatment option for symptom management in cancer patients. Although current evidence from basic science and clinical research on herbal medicines or acupuncture is still not sufficient to change oncological practice in general, the quality and design of clinical trials have significantly improved over the last few years which can provide patients with the most effective protocols or treatment types and safety profiles. Despite all the evidence presented, key challenges still exist including quality control of herbal medicinal materials, standardization of practices and current methodology in acupuncture,
TABLE 3: Contraindications and cautions for the use of acupuncture in breast cancer patients.

(1) Extreme needle phobia, very "strong reactors" to acupuncture

(2) Coagulopathy

(3) Immunocompromised patients or neutropenia (less $500 / \mathrm{mm}^{3}$ ) -risk of infection

(4) In young patients (age less than 18 years old) postsplenectomy - risk of infection

(5) Avoid directly onto a tumor nodule or into an ulcerative area

(6) In areas of spinal instability—risk of cord compression secondary to acupuncture's muscle relaxing properties

(7) Into a prosthesis-risk of leakage of saline/silicone

(8) Over intracranial deficits following neurosurgery

(9) Pregnancy

(10) Confused patients

and pharmacokinetic interaction between drug components or between chemotherapy and herbal medicine. Further research addressing these challenges in the form of rigorously designed clinical trials accompanied by comprehensive and in-depth laboratory studies is needed to improve the quality of the existing evidence base and support the use of CAM.

\section{Acknowledgments}

This work was supported by a Grant from the National Research Program for Biopharmaceuticals (NRPB) (NSC 102-2325-B-001-007), Taiwan. The authors would like to thank Miss Miranda Loney, Agricultural Biotechnology Research Center English Editor's Office, Academia Sinica, Taiwan, for English editorial assistance.

\section{References}

[1] American Cancer Society, Global Cancer Facts \& Figures, American Cancer Society, Atlanta, Ga, USA, 2nd edition, 2011.

[2] A. Jemal, F. Bray, M. M. Center, J. Ferlay, E. Ward, and D. Forman, "Global cancer statistics," CA: A Cancer Journal for Clinicians, vol. 61, no. 2, pp. 69-90, 2011.

[3] M. C. S. Araújo, I. L. Farias, J. Gutierres et al., "Uncaria tomentosa-adjuvant treatment for Breast Cancer: clinical trial," Evidence-Based Complementary and Alternative Medicine, vol. 2012, Article ID 676984, 88 pages, 2012.

[4] US Preventive Services Task Force, "Screening for Breast Cancer," http://www.uspreventiveservicestaskforce.org/uspstf/ uspsbrca.htm, 2009.

[5] Canadian Task Force on Preventive Health Care, "Screening for breast cancer," www.canadiantaskforce.ca/guidelines/2011breast-cancer/, 2011.

[6] J. T. Anim, B. John, S. A. AbdulSathar S et al., "Relationship between the expression of various markers and prognostic factors in breast cancer," Acta Histochemica, vol. 107, no. 2, pp. 87-93, 2005.

[7] K. Kado, A. Forsyth, P. Patel, and J. Schwartz, "Dietary supplements and natural products in Breast Cancer trials," Frontiers in Bioscience, vol. 4, pp. 546-567, 2012. 
[8] H. Ozer, J. O. Armitage, C. L. Bennett et al., "Update of recommendations for the use of hematopoietic colony-stimulating factors: evidence-based, clinical practice guidelines," Journal of Clinical Oncology, vol. 18, no. 20, pp. 3558-3585, 2000.

[9] C. F. Higgins, "Multiple molecular mechanisms for multidrug resistance transporters," Nature, vol. 446, no. 7137, pp. 749-757, 2007.

[10] C. Z. Wang, T. Calway, and C. S. Yuan, "Herbal medicines as adjuvants for Cancer therapeutics," The American Journal of Chinese Medicine, vol. 40, no. 4, pp. 657-669, 2012.

[11] World Health Organization, Guidelines on Safety Monitoring of Herbal Medicines in Pharmacovigilance Systems, World Health Organization, Geneva, Switzerland, 2004.

[12] Early Breast Cancer Trialists' Collaborative Group (EBCTCG), "Effects of chemo-therapy and hormonal therapy for early breast cancer on recurrence and 15-year survival: an overview of the randomised trials," The Lancet, vol. 365, no. 9472, pp. 16871717, 2005.

[13] A. H. Partridge, H. J. Burstein, and E. P. Winer, "Side effects of chemotherapy and combined chemohormonal therapy in women with early-stage breast cancer," Journal of the National Cancer Institute. Monographs, no. 30, pp. 135-142, 2001.

[14] M. N. Fornier, "Approved agents for metastatic breast cancer," Seminars in Oncology, vol. 38, supplement 2, pp. S3-S10, 2011.

[15] M. Tagliaferri, I. Cohen, and D. Tripathy, "Complementary and alternative medicine in early-stage breast cancer," Seminars in Oncology, vol. 28, no. 1, pp. 121-134, 2001.

[16] C. Yang, L. Y. Chien, and C. J. Tai, "Use of complementary and alternative medicine among patients with cancer receiving outpatient chemotherapy in Taiwan," Journal of Alternative and Complementary Medicine, vol. 14, no. 4, pp. 413-416, 2008.

[17] R. E. Patterson, M. L. Neuhouser, M. M. Hedderson et al., "Types of alternative medicine used by patients with breast, colon, or prostate cancer: predictors, motives, and costs," Journal of Alternative and Complementary Medicine, vol. 8, no. 4, pp. 477-485, 2002.

[18] L. K. Helyer, S. Chin, B. K. Chui et al., "The use of complementary and alternative medicines among patients with locally advanced breast cancer-a descriptive study," BMC Cancer, vol. 6, article 39, 2006.

[19] J. Shen, R. Andersen, P. S. Albert et al., "Use of complementary/alternative therapies by women with advanced-stage breast cancer," BMC Complementary and Alternative Medicine, vol. 2, no. $8,2002$.

[20] M. A. Navo, J. Phan, C. Vaughan et al., "An assessment of the utilization of complementary and alternative medication in women with gynecologic or breast malignancies," Journal of Clinical Oncology, vol. 22, no. 4, pp. 671-677, 2004.

[21] T. Risberg, A. Kolstad, Y. Bremnes et al., "Knowledge of and attitudes toward complementary and alternative therapies: a national multicentre study of oncology professionals in Norway," European Journal of Cancer, vol. 40, no. 4, pp. 529-535, 2004.

[22] K. Münstedt, A. Entezami, A. Wartenberg, and U. Kullmer, “The attitudes of physicians and oncologists towards unconventional cancer therapies (UCT)," European Journal of Cancer, vol. 36, no. 16, pp. 2090-2095, 2000.

[23] P. Harris and R. Rees, "The prevalence of complementary and alternative medicine use among the general population: a systematic review of the literature," Complementary Therapies in Medicine, vol. 8, no. 2, pp. 88-96, 2000.
[24] K. Nishimura, G. A. Plotnikoff, and K. Watanabe, "Kampo medicine as an integrative medicine in Japan," Japan Medical Association Journal, vol. 52, no. 3, pp. 147-149, 2009.

[25] H. L. Park, H. S. Lee, B. C. Shin et al., "Traditional medicine in China, Korea, and Japan: a brief introduction and comparison," Evidence-Based Complementary and Alternative Medicine, vol. 2012, Article ID 429103, 9 pages, 2012.

[26] A. Sparreboom, M. C. Cox, M. R. Acharya, and W. D. Figg, "Herbal remedies in the United States: potential adverse interactions with anticancer agents," Journal of Clinical Oncology, vol. 22, no. 12, pp. 2489-2503, 2004.

[27] D. M. Eisenberg, R. C. Kessler, M. I. Van Rompay et al., "Perceptions about complementary therapies relative to conventional therapies among adults who use both: results from a national survey," Annals of Internal Medicine, vol. 135, no. 5, pp. 344-351, 2001.

[28] Z. Hu, X. Yang, P. C. L. Ho et al., "Herb-drug interactions: a literature review," Drugs, vol. 65, no. 9, pp. 1239-1282, 2005.

[29] M. B. Cleary-Guida, H. A. Okvat, M. C. Oz, and W. Ting, "A regional survey of health insurance coverage for complementary and alternative medicine: current status and future ramifications," Journal of Alternative and Complementary Medicine, vol. 7, no. 3, pp. 269-273, 2001.

[30] A. K. Garg, T. A. Buchholz, and B. B. Aggarwal, "Chemosensitization and radiosensitization of tumors by plant polyphenols," Antioxidants and Redox Signaling, vol. 7, no. 11-12, pp. 1630-1647, 2005.

[31] V. B. Konkimalla and T. Efferth, "Evidence-based Chinese medicine for cancer therapy," Journal of Ethnopharmacology, vol. 116, no. 2, pp. 207-210, 2008.

[32] D. Hann, F. Baker, M. Denniston, and N. Entrekin, "Longterm breast cancer survivors' use of complementary therapies: perceived impact on recovery and prevention of recurrence," Integrative Cancer Therapies, vol. 4, no. 1, pp. 14-20, 2005.

[33] T. Efferth, P. C. H. Li, V. S. B. Konkimalla, and B. Kaina, "From traditional Chinese medicine to rational cancer therapy," Trends in Molecular Medicine, vol. 13, no. 8, pp. 353-361, 2007.

[34] C. Yang, L. Chien, and C. Tai, "Use of complementary and alternative medicine among patients with cancer receiving outpatient chemotherapy in Taiwan," Journal of Alternative and Complementary Medicine, vol. 14, no. 4, pp. 413-416, 2008.

[35] A. M. Gross, Q. Liu, and S. Bauer-Wu, "Prevalence and predictors of complementary therapy use in advanced-stage breast cancer patients," Journal of Oncology Practice, vol. 3, no. 6, pp. 292-295, 2007.

[36] J. L. McQuade, Z. Meng, Z. Chen et al., "Utilization of and attitudes towards traditional Chinese medicine therapies in a Chinese Cancer hospital: a survey of patients and physicians," Evidence-Based Complementary and Alternative Medicine, vol. 2012, Article ID 504507, 11 pages, 2012.

[37] G. E. Deng, M. Frenkel, L. Cohen et al., "Evidence-based clinical practice guidelines for integrative oncology: complementary therapies and botanicals," Journal of the Society for Integrative Oncology, vol. 7, no. 3, pp. 85-120, 2009.

[38] G. Deng and B. R. Cassileth, "Integrative oncology: complementary therapies for pain, anxiety, and mood disturbance," CA: A Cancer Journal for Clinicians, vol. 55, no. 2, pp. 109-116, 2005.

[39] E. C. Devine and S. K. Westlake, "The effects of psychoeducational care provided to adults with cancer: meta-analysis of 116 studies," Oncology Nursing Forum, vol. 22, no. 9, pp. 1369-1381, 1995. 
[40] D. Seely and D. Oneschuk, "Interactions of natural health products with biomedical cancer treatments," Current Oncology, vol. 15, supplement 2, pp. 81-86, 2008.

[41] D. O'Regan and J. Filshie, "Acupuncture and cancer," Autonomic Neuroscience, vol. 157, no. 1-2, pp. 96-100, 2010.

[42] J. Saquib, L. Madlensky, S. Kealey et al., "Classification of CAM use and its correlates in patients with early-stage breast cancer," Integrative Cancer Therapies, vol. 10, no. 2, pp. 138-147, 2011.

[43] B. Gerber, C. Scholz, T. Reimer, V. Briese, and W. Janni, "Complementary and alternative therapeutic approaches in patients with early breast cancer: a systematic review," Breast Cancer Research and Treatment, vol. 95, no. 3, pp. 199-209, 2006.

[44] Z. Nahleh and I. A. Tabbara, "Complementary and alternative medicine in breast cancer patients," Palliative \& Supportive Care, vol. 1, no. 3, pp. 267-273, 2003.

[45] E. A. Lammerink, G. H. de Bock, C. P. Schröder, and M. J. Mourits, "The management of menopausal symptoms in breast cancer survivors: case-based approach," Maturitas, vol. 73, no. 3, pp. 265-268, 2012.

[46] H. Kang, D. Jeong, D. Kim, and M. S. Lee, "The use of acupuncture for managing gynaecologic conditions: an overview of systematic reviews," Maturitas, vol. 68, no. 4, pp. 346-354, 2011.

[47] S. Loibl, A. Lintermans, A. S. Dieudonné, and P. Neven, "Management of menopausal symptoms in breast cancer patients," Maturitas, vol. 68, no. 2, pp. 148-154, 2011.

[48] "Practicing Chiropractors' Committee on Radiology Protocols," http://www.pccrp.org/docs/PCCRP\%20Section\%20I.pdf, 2013.

[49] US Department of Heath and Human Services and Agency for Healthcare Research and Quality, http://www.ahrq.gov, 2013.

[50] G. Del Rio, S. Zironi, L. Valeriani et al., "Weight gain in women with breast cancer treated with adjuvant cyclophosphomide, methotrexate and 5-fluorouracil. Analysis of resting energy expenditure and body composition," Breast Cancer Research and Treatment, vol. 73, no. 3, pp. 267-273, 2002.

[51] J. Weis, "Cancer-related fatigue: prevalence, assessment and treatment strategies," Expert Review of Pharmacoeconomics and Outcomes Research, vol. 11, no. 4, pp. 441-446, 2011.

[52] R. Stasi, L. Abriani, P. Beccaglia, E. Terzoli, and S. Amadori, "Cancer-related fatigue: evolving concepts in evaluation and treatment," Cancer, vol. 98, no. 9, pp. 1786-1801, 2003.

[53] G. F. V. Ismael, D. D. Rosa, M. S. Mano, and A. Awada, "Novel cytotoxic drugs: old challenges, new solutions," Cancer Treatment Reviews, vol. 34, no. 1, pp. 81-91, 2008.

[54] X. Yao, K. Panichpisal, N. Kurtzman, and K. Nugent, "Cisplatin nephrotoxicity: a review," American Journal of the Medical Sciences, vol. 334, no. 2, pp. 115-124, 2007.

[55] L. Christie, M. M. Acharya, V. K. Parihar, A. Nguyen, V. Martirosian, and C. L. Limoli, "Impaired cognitive function and hippocampal neurogenesis following cancer chemotherapy," Clinical Cancer Research, vol. 18, no. 7, pp. 1954-1965, 2012.

[56] L. Gianni, B. F. Cole, I. Panzini et al., "Anemia during adjuvant non-taxane chemotherapy for early breast cancer: incidence and risk factors from two trials of the International Breast Cancer Study Group," Supportive Care in Cancer, vol. 16, no. 1, pp. 67-74, 2008.

[57] R. Ochoa, P. A. Bejarano, S. Glück, and A. J. Montero, "Pneumonitis and pulmonary fibrosis in a patient receiving adjuvant docetaxel and cyclophosphamide for stage 3 breast cancer: a case report and literature review," Journal of Medical Case Reports, vol. 6, article 413, 2012.
[58] A. F. Carrion, P. J. Hosein, E. M. Cooper, G. Lopes, L. Pelaez, and C. M. Rocha-Lima, "Severe colitis associated with docetaxel use: a report of four cases," World Journal of Gastrointestinal Oncology, vol. 2, no. 10, pp. 390-394, 2010.

[59] M. Crump, D. Tu, L. Shepherd, M. Levine, V. Bramwell, and K. Pritchard, "Risk of acute leukemia following epirubicin-based adjuvant chemotherapy: a report from the National Cancer Institute of Canada Clinical Trials Group," Journal of Clinical Oncology, vol. 21, no. 16, pp. 3066-3071, 2003.

[60] C. J. Poole, H. M. Earl, L. Hiller et al., "Epirubicin and cyclophosphamide, methotrexate, and fluorouracil as adjuvant therapy for early breast cancer," The New England Journal of Medicine, vol. 355, no. 18, pp. 1851-1862, 2006.

[61] K. A. Amin, B. M. Mohamed, M. A. El-Wakil, and S. O. Ibrahem, "Impact of breast cancer and combination chemotherapy on oxidative stress, hepatic and cardiac markers," Journal of Breast Cancer, vol. 15, no. 3, pp. 306-312, 2012.

[62] G. P. Stathopoulos, J. Koutantos, H. Lazaki, S. K. Rigatos, J. Stathopoulos, and G. Deliconstantinos, "Capecitabine (Xeloda) as monotherapy in advanced breast and colorectal cancer: effectiveness and side-effects," Anticancer Research, vol. 27, no. 3B, pp. 1653-1656, 2007.

[63] K. D. Chandwani, J. L. Ryan, L. J. Peppone et al., "Cancer-related stress and complementary and alternative medicine: a review," Evidence-Based Complementary and Alternative Medicine, vol. 2012, Article ID 979213, 15 pages, 2012.

[64] T. J. Powles, A. L. Jones, I. R. Judson, J. R. Hardy, and S. E. Ashley, "A randomised trial comparing combination chemotherapy using mitomycin $\mathrm{C}$, mitozantrone and methotrexate (3M) with vincristine, anthracycline and cyclophosphamide (VAC) in advanced breast cancer," British Journal of Cancer, vol. 64, no. 2, pp. 406-410, 1991.

[65] U. S. National Cancer Institute, www.cancer.gov/cancertopics/ druginfo/breastcancer, 2012.

[66] Z. Ghoreishi, A. Esfahani, A. Djazayeri et al., "Omega-3 fatty acids are protective against paclitaxel-induced peripheral neuropathy: a randomized double-blind placebo controlled trial," BMC Cancer, vol. 12, pp. 355-363, 2012.

[67] S. Saibil, B. Fitzgerald, O. C. Freedman et al., "Incidence of taxane-induced pain and distress in patients receiving chemotherapy for early-stage breast cancer: a retrospective, outcomes-based survey," Current Oncology, vol. 17, no. 4, pp. 4247, 2010.

[68] B. Fisher, J. P. Costantino, D. L. Wickerham et al., "Tamoxifen for the prevention of breast cancer: current status of the National Surgical Adjuvant Breast and Bowel Project P-1 study," Journal of the National Cancer Institute, vol. 97, no. 22, pp. 16521662, 2005.

[69] A. Sparber, L. Bauer, G. Curt et al., "Use of complementary medicine by adult patients participating in cancer clinical trials," Oncology Nursing Forum, vol. 27, no. 4, pp. 623-630, 2000.

[70] J. Lu, J. Bao, X. Chen, M. Huang, and Y. Wang, "Alkaloids isolated from natural herbs as the anticancer agents," EvidenceBased Complementary and Alternative Medicine, vol. 2012, Article ID 485042, 12 pages, 2012.

[71] Z. Xu, X. Chen, Z. Zhong, L. Chen, and Y. Wang, “Ganoderma lucidum polysaccharides: immunomodulation and potential anti-tumor activities," American Journal of Chinese Medicine, vol. 39, no. 1, pp. 15-27, 2011.

[72] H. Liao, M. Lu, H. Chang et al., "Effects of herbal medicinal formulas on suppressing viral replication and modulating 
immune responses," American Journal of Chinese Medicine, vol. 38, no. 1, pp. 173-190, 2010.

[73] J. N. Lai, C. T. Wu, and J. D. Wang, "Prescription pattern of Chinese herbal products for Breast Cancer in Taiwan: a population-based study," Evidence-Based Complementary and Alternative Medicine, vol. 2012, Article ID 891893, 7 pages, 2012.

[74] T. Yasui, S. Matsui, S. Yamamoto et al., "Effects of Japanese traditional medicines on circulating cytokine levels in women with hot flashes," Menopause, vol. 18, no. 1, pp. 85-92, 2011.

[75] B. Yang, H. Li, Y. Qi, and M. Lu, "Clinical study on treatment of mammary cancer by Shenqi Fuzheng Injection in cooperation with chemotherapy," Chinese Journal of Integrative Medicine, vol. 13, no. 1, pp. 37-40, 2007.

[76] N. Yaal-Hahoshen, Y. Maimon, N. Siegelmann-Danieli et al., "A prospective, controlled study of the botanical compound mixture LCS101 for chemotherapy-induced hematological complications in breast cancer," Oncologist, vol. 16, no. 9, pp. 11971202, 2011.

[77] L. P. Liu, J. F. Liu, and Y. Q. Lu, "Effects of Sheng-Mai injection on the PRPP synthetase activity in BFU-es and CFU-es from bone marrows of mice with benzene-induced aplastic anemia," Life Sciences, no. 69, pp. 1373-1379, 2001.

[78] M. Wang, J. Li, H. Di et al., "Clinical study on effect of Astragalus Injection and its immuno-regulation action in treating chronic aplastic anemia," Chinese Journal of Integrative Medicine, vol. 13, no. 2, pp. 98-102, 2007.

[79] H. Que, H. Chen, S. Gao et al., "Effect of Runing II on the growth and metastasis of transplanted tumor in mammary cancerbearing mice and its mechanism," Journal of Traditional Chinese Medicine, vol. 28, no. 4, pp. 293-298, 2008.

[80] S. Liu, Y. Hua, Z. Sun, S. Tan, and D. Lu, "Clinical observation of Ruyiping in preventing recidivation and metastasis of breast cancer," Journal of Chinese Integrative Medicine, vol. 5, no. 2, pp. 147-149, 2007.

[81] Z. Dai, X. Wang, H. Kang et al., "Clinical effects of Shenqi Fuzheng Injection in the neoadjuvant chemotherapy for local advanced breast cancer and the effects on T-lymphocyte subsets," Journal of Traditional Chinese Medicine, vol. 28, no. 1, pp. 34-38, 2008.

[82] M. F. Miller, K. M. Bellizzi, M. Sufian, A. H. Ambs, M. S. Goldstein, and R. Ballard-Barbash, "Dietary supplement use in individuals living with Cancer and other chronic conditions: a population-based study," Journal of the American Dietetic Association, vol. 108, no. 3, pp. 483-494, 2008.

[83] J. Jiang, A. Thyagarajan-Sahu, J. Loganathan et al., "BreastDefend prevents breast-to-lung cancer metastases in an orthotopic animal model of triple-negative human breast cancer," Oncology Reports, vol. 28, no. 4, pp. 1139-1145, 2012.

[84] J. Jiang, R. Wojnowski, A. Jedinak, and D. Sliva, "Suppression of proliferation and invasive behavior of human metastatic breast cancer cells by dietary supplement BreastDefend," Integrative Cancer Therapies, vol. 10, no. 2, pp. 192-200, 2011.

[85] S. R. Zhuang, H. F. Chiu, S. L. Chen et al., "Effects of a Chinese medical herbs complex on cellular immunity and toxicityrelated conditions of breast cancer patients," British Journal of Nutrition, vol. 107, no. 5, pp. 712-718, 2012.

[86] S. Zhuang, S. Chen, J. Tsai et al., "Effect of citronellol and the Chinese medical herb complex on cellular immunity of cancer patients receiving chemotherapy/radiotherapy," Phytotherapy Research, vol. 23, no. 6, pp. 785-790, 2009.

[87] H. S. Li, B. Yang, and X. C. Su, "Effect of shenqi fuzheng injection on repairing the immune function in patients with breast cancer," Zhongguo Zhong Xi Yi Jie He Za Zhi, vol. 29, no. 6, pp. 537-539, 2009.

[88] T. Mellios, H. L. Ko, and J. Beuth, "Impact of adjuvant chemoand radiotherapy on the cellular immune system of breast cancer patients," In Vivo, vol. 24, no. 2, pp. 227-230, 2010.

[89] C. Wong, Y. Bao, E. L. Wong, P. Leung, K. P. Fung, and C. W. K. Lam, "Immunomodulatory activities of Yunzhi and Danshen in post-treatment breast cancer patients," American Journal of Chinese Medicine, vol. 33, no. 3, pp. 381-395, 2005.

[90] W. Yang, J. Ju, M. J. Jeon, X. Han, and I. Shin, "Danshen (Salvia miltiorrhiza) extract inhibits proliferation of breast cancer cells via modulation of akt activity and p27 level," Phytotherapy Research, vol. 24, no. 2, pp. 198-204, 2010.

[91] L. Wang, Y. Ling, Y. Chen et al., "Flavonoid baicalein suppresses adhesion, migration and invasion of MDA-MB-231 human breast cancer cells," Cancer Letters, vol. 297, no. 1, pp. 42-48, 2010.

[92] B. A. Pockaj, C. L. Loprinzi, J. A. Sloan et al., "Pilot evaluation of black cohosh for the treatment of hot flashes in women," Cancer Investigation, vol. 22, no. 4, pp. 515-521, 2004.

[93] V. C. K. Wong, C. E. D. Lim, X. Luo, and W. S. F. Wong, "Current alternative and complementary therapies used in menopause," Gynecological Endocrinology, vol. 25, no. 3, pp. 166-174, 2009.

[94] C. Rotem and B. Kaplan, "Phyto-Female Complex for the relief of hot flushes, night sweats and quality of sleep: randomized, controlled, double-blind pilot study," Gynecological Endocrinology, vol. 23, no. 2, pp. 117-122, 2007.

[95] A. Sammartino, G. A. Tommaselli, V. Gargano, C. Di Carlo, W. Attianese, and C. Nappi, "Short-term effects of a combination of isoflavones, lignans and Cimicifuga racemosa on climacteric-related symptoms in postmenopausal women: a double-blind, randomized, placebo-controlled trial," Gynecological Endocrinology, vol. 22, no. 11, pp. 646-650, 2006.

[96] N. Morabito, A. Crisafulli, C. Vergara et al., "Effects of genistein and hormone-replacement therapy on bone loss in early postmenopausal women: a randomized double-blind placebocontrolled study," Journal of Bone and Mineral Research, vol. 17, no. 10, pp. 1904-1912, 2002.

[97] M. Rhyu, J. Lu, D. E. Webster, D. S. Fabricant, N. R. Farnsworth, and Z. J. Wang, "Black cohosh (Actaea racemosa, Cimicifuga racemosa) behaves as a mixed competitive ligand and partial agonist at the human $\mu$ opiate receptor," Journal of Agricultural and Food Chemistry, vol. 54, no. 26, pp. 9852-9857, 2006.

[98] S. Frei-Kleiner, W. Schaffner, V. W. Rahlfs, C. Bodmer, and M. Birkhäuser, "Cimicifuga racemosa dried ethanolic extract in menopausal disorders: a double-blind placebo-controlled clinical trial," Maturitas, vol. 51, no. 4, pp. 397-404, 2005.

[99] K. M. Newton, S. D. Reed, A. Z. LaCroix, L. C. Grothaus, K. Ehrlich, and J. Guiltinan, "Treatment of vasomotor symptoms of menopause with black cohosh, multibotanicals, soy, hormone therapy, or placebo: a randomized trial," Annals of Internal Medicine, vol. 145, no. 12, pp. 869-879, 2006.

[100] M. D. J. Molla, J. J. Hidalgo-Mora, and M. G. Soteras, "Phytotherapy as alternative to hormone replacement therapy," Frontiers in Bioscience, vol. 3, pp. 191-204, 2011.

[101] J. X. Liu, J. Y. Zhou, and T. F. Liu, "Phase III clinical trial for Yun Zhi polysaccharide (PSP) capsules," in Advanced Research in PSP, Q. Y. Yang, Ed., pp. 295-303, Hong Kong Association for Health Care, Hong Kong, China, 1999.

[102] T. W. Sun and Y. P. Zhu, "The effect of PSP on immune function and living quality in patients receiving chemotherapy 
for gynecological malignancies," in Advanced Research in PSP, Q. Y. Yang, Ed., pp. 308-329, Hong Kong Association for Health Care, Hong Kong, China, 1999.

[103] W. L. Y. Eliza, C. K. Fai, and L. P. Chung, "Efficacy of Yun Zhi (coriolus versicolor) on survival in cancer patients: systematic review and meta-analysis," Recent Patents on Inflammation and Allergy Drug Discovery, vol. 6, no. 1, pp. 78-87, 2012.

[104] Z. Pang, Y. Chen, and M. Zhou, "Polysaccharide Krestin Enhances Manganese Superoxide Dismutase Activity and mRNA Expression in Mouse Peritoneal Macrophages," American Journal of Chinese Medicine, vol. 28, no. 3-4, pp. 331-341, 2000.

[105] M. Fisher and L. Yang, "Anticancer effects and mechanisms of polysaccharide-K (PSK): implications of cancer immunotherapy," Anticancer Research, vol. 22, no. 3, pp. 1737-1754, 2002.

[106] S. Kudo, J. Tanaka, H. Kashida, Y. Tamegai, S. Endo, and H. Yamano, "Effectiveness of immunochemotherapy with PSK, a protein-bound polysaccharide, in colorectal cancer and changes of tumor marker," Oncology reports, vol. 9, no. 3, pp. 635-638, 2002.

[107] S. Bokmand and S. Flyger, "Acupuncture relieves menopausal discomfort in breast cancer patients: a prospective, double blinded, randomized study," Breast, vol. 22, no. 3, pp. 320-323, 2013.

[108] J. L. Otte, J. S. Carpenter, X. Zhong, and P. A. S. Johnstone, "Feasibility study of acupuncture for reducing sleep disturbances and hot flashes in postmenopausal breast cancer survivors," Clinical Nurse Specialist, vol. 25, no. 5, pp. 228-236, 2011.

[109] A. Liljegren, P. Gunnarsson, B. Landgren, N. Robéus, H. Johansson, and S. Rotstein, "Reducing vasomotor symptoms with acupuncture in breast cancer patients treated with adjuvant tamoxifen: a randomized controlled trial," Breast Cancer Research and Treatment, pp. 1-8, 2010.

[110] B. A. De Valois, T. E. Young, N. Robinson, C. McCourt, and E. J. Maher, "Using traditional acupuncture for breast cancerrelated hot flashes and night sweats," Journal of Alternative and Complementary Medicine, vol. 16, no. 10, pp. 1047-1057, 2010.

[111] J. Hervik and O. Mjåland, "Acupuncture for the treatment of hot flashes in breast cancer patients, a randomized, controlled trial," Breast Cancer Research and Treatment, vol. 116, no. 2, pp. 311316, 2009.

[112] J. Frisk, S. Carlhäll, A.-C. Källström, L. Lindh-Åstrand, A. Malmström, and M. Hammar, "Long-term follow-up of acupuncture and hormone therapy on hot flushes in women with breast cancer: a prospective, randomized, controlled multicenter trial," Climacteric, vol. 11, no. 2, pp. 166-174, 2008.

[113] G. Deng, A. Vickers, S. Yeung, and B. Cassileth, "Randomized, controlled trial of acupuncture for the treatment of hot flashes in breast cancer patients," Journal of Clinical Oncology, vol. 25, no. 35, pp. 5584-5590, 2007.

[114] E. Nedstrand, Y. Wyon, M. Hammar, and K. Wijma, "Psychological well-being improves in women with breast cancer after treatment with applied relaxation or electro-acupuncture for vasomotor symptom," Journal of Psychosomatic Obstetrics and Gynecology, vol. 27, no. 4, pp. 193-199, 2006.

[115] J. S. Carpenter, N. Wells, B. Lambert et al., "A pilot study of magnetic therapy for hot flashes after breast cancer," Cancer Nursing, vol. 25, no. 2, pp. 104-109, 2002.

[116] G. Porzio, T. Trapasso, S. Martelli et al., "Acupuncture in the treatment of menopause-related symptoms in women taking tamoxifen," Tumori, vol. 88, no. 2, pp. 128-130, 2002.
[117] S. Choo, K. Kong, W. Lim, F. Gao, K. Chua, and S. Leong, "Electroacupuncture for refractory acute emesis caused by chemotherapy," Journal of Alternative and Complementary Medicine, vol. 12, no. 10, pp. 963-969, 2006.

[118] S. L. Dibble, J. Luce, B. A. Cooper et al., "Acupressure for chemotherapy-induced nausea and vomiting: a randomized clinical trial," Oncology Nursing Forum, vol. 34, no. 4, pp. 813820, 2007.

[119] A. Molassiotis, A. M. Helin, R. Dabbour, and S. Hummerston, "The effects of P6 acupressure in the prophylaxis of chemotherapy-related nausea and vomiting in breast cancer patients," Complementary Therapies in Medicine, vol. 15, no. 1, pp. 3-12, 2007.

[120] S. L. Dibble, J. Chapman, K. A. Mack, and A. S. Shih, "Acupressure for nausea: results of a pilot study," Oncology Nursing Forum, vol. 27, no. 1, pp. 41-47, 2000.

[121] J. Shen, N. Wenger, J. Glaspy et al., "Electroacupuncture for control of myeloablative chemotherapy-induced emesis: a randomized controlled trial," Journal of the American Medical Association, vol. 284, no. 21, pp. 2755-2761, 2000.

[122] S. Gu, J. Yang, and M. Zhang, "Contrast study for the effects of different administration route of dexamethasone on gastrointestinal reaction induced by chemotherapy," Journal of Nurses Training, vol. 22, no. 5, pp. 399-400, 2007.

[123] Y. F. Ho, "Acupressure and psychological intervention for emesis due to chemotherapy on the patients with mammary cancer," Guangxi Medical Journal, vol. 28, no. 5, pp. 738-739, 2006.

[124] Y. Xu, J. L. Wang, and H. Y. Du, "Contrast observation on injection metoclopramide in acupuncture point for the treatment of emesis after chemical treatment to 100 patients with cancer," Central Plains Medical Journal, vol. 32, no. 15, p. 58, 2005.

[125] C. H. Ning, "Contrast observation on injection metoclopramide in different acupuncture point for the treatment of emesis after chemical treatment to mammary cancer," Hunan Guiding Journal of Traditional Chinese Medicine, vol. 10, no. 2, pp. 39-41, 2004.

[126] E. Nystrom, G. Ridderstrom, and A. Leffler, "Manual acupuncture as an adjunctive treatment of nausea in patients with cancer in palliative care-a prospective, observational pilot study," Acupuncture in Medicine, vol. 26, no. 1, pp. 27-32, 2008.

[127] W. E. Mehling, B. Jacobs, M. Acree et al., "Symptom management with massage and acupuncture in postoperative Cancer patients: a randomized controlled trial," Journal of Pain and Symptom Management, vol. 33, no. 3, pp. 258-266, 2007.

[128] J. Liang, L. P. Wang, and G. N. Wang, "The effect of preemptive HAN'S acupoint nerve stimulator on postoperative pain in patients undergoing radical mastectomy," Journal of Harbin Medical University, vol. 41, no. 6, pp. 607-609, 2007.

[129] J. P. He, M. Friedrich, A. K. Ertan, K. Müller, and W. Schmidt, "Pain-relief and movement improvement by acupuncture after ablation and axillary lymphadenectomy in patients with mammary cancer," Clinical and Experimental Obstetrics and Gynecology, vol. 26, no. 2, pp. 81-84, 1999.

[130] T. Bao, L. Cai, J. T. Giles et al., "A dual-center randomized controlled double blind trial assessing the effect of acupuncture in reducing musculoskeletal symptoms in breast cancer patients taking aromatase inhibitors," Breast Cancer Research and Treatment, vol. 138, no. 1, pp. 167-174, 2013.

[131] K. D. Crew, J. L. Capodice, H. Greenlee et al., "Randomized, blinded, sham-controlled trial of acupuncture for the management of aromatase inhibitor-associated joint symptoms 
in women with early-stage breast cancer," Journal of Clinical Oncology, vol. 28, no. 7, pp. 1154-1160, 2010.

[132] J. J. Mao, D. W. Bruner, C. Stricker et al., "Feasibility trial of electroacupuncture for aromatase inhibitor-related arthralgia in breast cancer survivors," Integrative Cancer Therapies, vol. 8, no. 2, pp. 123-129, 2009.

[133] B. R. Cassileth, K. J. Van Zee, Y. Chan et al., "A safety and efficacy pilot study of acupuncture for the treatment of chronic lymphoedema," Acupuncture in Medicine, vol. 29, no. 3, pp. 170172, 2011.

[134] M. Alem and M. S. C. Gurgel, "Acupuncture in the rehabilitation of women after breast cancer surgery-a case series," Acupuncture in Medicine, vol. 26, no. 2, pp. 86-93, 2008.

[135] S. T. Sun, G. Y. Nan, and Y. L. Lee, "Observation on injection g-csf in acupuncture point for the treatment of leukopenia after chemical treatment to 102 patients with mammary cancer," World Health Digest Journal of New Medicine, vol. 4, no. 6, p. 50, 2007.

[136] B. Y. Chang and B. H. Lian, "Observation on injection in acupuncture point for the treatment of leukopenia after chemical treatment to 45 patients with cancer," Journal of Practical and Traditional Chinese Medicine, vol. 18, no. 2, p. 30, 2002.

[137] K. W. Tsang, C. L. Lam, C. Yan et al., "coriolus versicolor polysaccharide peptide slows progression of advanced nonsmall cell lung cancer," Respiratory Medicine, vol. 97, no. 6, pp. 618-624, 2003.

[138] M. Fisher and L. Yang, "Anticancer effects and mechanisms of polysaccharide-K (PSK): implications of cancer immunotherapy," Anticancer Research, vol. 22, no. 3, pp. 1737-1754, 2002.

[139] P. M. Kidd, "The use of mushroom glucans and proteoglycans in cancer treatment," Alternative Medicine Review, vol. 5, no. 1, pp. 4-27, 2000.

[140] J. W. M. Yuen and M. D. I. Gohel, "Anticancer effects of Ganoderma lucidum: a review of scientific evidence," Nutrition and Cancer, vol. 53, no. 1, pp. 11-17, 2005.

[141] H. Zhao, Q. Zhang, L. Zhao, X. Huang, J. Wang, and X. Kang, "Spore powder of Ganoderma lucidum improves cancerrelated fatigue in breast cancer patients undergoing endocrine therapy: a pilot clinical trial," Evidence-based Complementary and Alternative Medicine, vol. 2012, Article ID 809614, 8 pages, 2012.

[142] Z. Xu, X. Chen, Z. Zhong, L. Chen, and Y. Wang, "Ganoderma lucidum polysaccharides: immunomodulation and potential anti-tumor activities," American Journal of Chinese Medicine, vol. 39, no. 1, pp. 15-27, 2011.

[143] C. Weng and G. Yen, "The in vitro and in vivo experimental evidences disclose the chemopreventive effects of Ganoderma lucidum on cancer invasion and metastasis," Clinical and Experimental Metastasis, vol. 27, no. 5, pp. 361-369, 2010.

[144] G. Wu, J. Lu, J. Guo et al., "Ganoderic acid DM, a natural triterpenoid, induces DNA damage, G1 cell cycle arrest and apoptosis in human breast cancer cells," Fitoterapia, vol. 83, no. 2, pp. 408-414, 2012.

[145] P. P. Bao, W. Lu, Y. Cui et al., "Ginseng and Ganoderma lucidum use after breast cancer diagnosis and quality of life: a report from the Shanghai Breast Cancer Survival Study," PLoS One, vol. 7, no. 6, Article ID e39343.

[146] C. I. Coleman, J. H. Hebert, and P. Reddy, “The effects of Panax ginseng on quality of life," Journal of Clinical Pharmacy and Therapeutics, vol. 28, no. 1, pp. 5-15, 2003.
[147] Y. Cui, X. Shu, Y. Gao, H. Cai, M. Tao, and W. Zheng, "Association of ginseng use with survival and quality of life among breast cancer patients," American Journal of Epidemiology, vol. 163, no. 7, pp. 645-653, 2006.

[148] B. K. Vogler, M. H. Pittler, and E. Ernst, "The efficacy of ginseng. A systematic review of randomised clinical trials," European Journal of Clinical Pharmacology, vol. 55, no. 8, pp. 567-575, 1999.

[149] W. Lu, Y. Cui, Y. Zheng et al., "Impact of newly diagnosed breast cancer on quality of life among Chinese women," Breast Cancer Research and Treatment, vol. 102, no. 2, pp. 201-210, 2007.

[150] A. H. Wu, M. C. Yu, C. Tseng, J. Hankin, and M. C. Pike, "Green tea and risk of breast cancer in Asian Americans," International Journal of Cancer, vol. 106, no. 4, pp. 574-579, 2003.

[151] A. H. Wu, D. Spicer, F. Z. Stanczyk, C. Tseng, C. S. Yang, and M. C. Pike, "Effect of 2-month controlled green tea intervention on lipoprotein cholesterol, glucose, and hormone levels in healthy postmenopausal women," Cancer Prevention Research, vol. 5, no. 3, pp. 393-402, 2012.

[152] N. R. Stendell-Hollis, C. A. Thomson, P. A. Thompson, J. W. Bea, E. C. Cussler, and I. A. Hakim, "Green tea improves metabolic biomarkers, not weight or body composition: a pilot study in overweight breast cancer survivors," Journal of Human Nutrition and Dietetics, vol. 23, no. 6, pp. 590-600, 2010.

[153] T. Luo, J. Wang, Y. Yin et al., “(-)-Epigallocatechin gallate sensitizes breast cancer cells to paclitaxel in a murine model of breast carcinoma," Breast Cancer Research, vol. 12, no. 1, article R8, 2010.

[154] J. J. Dignam, K. Wieand, K. A. Johnson et al., "Effects of obesity and race on prognosis in lymph node-negative, estrogen receptor-negative breast cancer," Breast Cancer Research and Treatment, vol. 97, no. 3, pp. 245-254, 2006.

[155] J. Eisenbraun, R. Scheer, M. Kröz, F. Schad, and R. Huber, "Quality of life in breast cancer patients during chemotherapy and concurrent therapy with a mistletoe extract," Phytomedicine, vol. 18, no. 2-3, pp. 151-157, 2011.

[156] M. A. Horneber, G. Bueschel, R. Huber, K. Linde, and M. Rostock, "Mistletoe therapy in oncology," Cochrane Database of Systematic Reviews, no. 2, Article ID CD003297, 2008.

[157] J. Beuth, B. Schneider, and J. M. Schierholz, "Impact of complementary treatment of breast cancer patients with standardized mistletoe extract during aftercare: a controlled multicenter comparative Epidemiological Cohort Study," Anticancer Research, vol. 28, no. 1B, pp. 523-527, 2008.

[158] A. Büssing, C. Stumpf, W. Tröger, and M. Schietzel, "Course of mitogen-stimulated $\mathrm{T}$ lymphocytes in cancer patients treated with Viscum album extracts," Anticancer Research, vol. 27, no. 4C, pp. 2903-2910, 2007.

[159] J. Eggenschwiler, A. Patrignani, U. Wagner et al., "Gene expression profiles of different breast cancer cells compared with their responsiveness to fermented mistletoe (Viscum album L.) extracts Iscador from oak (Quercus), pine (Pinus), white fir (Abies) and apple tree (Malus) in vitro," Arzneimittel-Forschung, vol. 56, no. 6A, pp. 483-496, 2006.

[160] V. Bocci, "Mistletoe (Viscum album) lectins as cytokine inducers and immunoadjuvant in tumor therapy. A review," Journal of Biological Regulators and Homeostatic Agents, vol. 7, no. 1, pp. 1-6, 1993.

[161] V. F. Semiglazov, V. V. Stepula, A. Dudov, J. Schnitker, and U. Mengs, "Quality of life is improved in breast cancer patients by standardised mistletoe extract PS76A2 during chemotherapy 
and follow-up: a randomised, placebo-controlled, double-blind, multicentre clinical trial," Anticancer Research, vol. 26, no. 2B, pp. 1519-1529, 2006.

[162] V. F. Semiglasov, V. V. Stepula, A. Dudov, W. Lehmacher, and U. Mengs, "The standardised mistletoe extract PS76A2 improves QoL in patients with breast Cancer Receiving adjuvant CMF chemotherapy: a randomised, placebo-controlled, double-blind, multicentre clinical trial," Anticancer Research, vol. 24, no. 2C, pp. 1293-1302, 2004.

[163] P. Fritz, J. Dippon, T. Kierschke et al., "Impact of mistletoe lectin binding in Breast Cancer," Anticancer Research, vol. 24, no. 2C, pp. 1187-1192, 2004.

[164] S. Johansson, J. Gullbo, P. Lindholm et al., "Small, novel proteins from the mistletoe Phoradendron tomentosum exhibit highly selective cytotoxicity to human breast cancer cells," Cellular and Molecular Life Sciences, vol. 60, no. 1, pp. 165-175, 2003.

[165] A. Büssing, W. Tröger, C. Stumpf, and M. Schietzel, "Local reactions to treatments with Viscum album $L$. extracts and their association with T-lymphocyte subsets and quality of life," Anticancer Research, vol. 28, no. 3B, pp. 1893-1897, 2008.

[166] W. T. Y. Loo, L. Jin, L. W. C. Chow, M. N. B. Cheung, and M. Wang, "Rhodiola algida improves chemotherapy-induced oral mucositis in breast cancer patients," Expert Opinion on Investigational Drugs, vol. 19, no. 1, pp. S91-S100, 2010.

[167] M. Abidov, S. Grachev, R. D. Seifulla, and T. N. Ziegenfuss, "Extract of Rhodiola rosea radix reduces the level of C-reactive protein and creatinine kinase in the blood," Bulletin of Experimental Biology and Medicine, vol. 138, no. 1, pp. 63-64, 2004.

[168] O. A. Bocharova, B. P. Matveev, A. I. Baryshnikov, K. M. Figurin, R. V. Serebriakova, and N. B. Bodrova, "The effect of a Rhodiola rosea extract on the incidence of recurrences of a superficial bladder cancer (experimental clinical research)," Urologiya $i$ Nefrologiya, no. 2, pp. 46-47, 1995.

[169] M. J. Campbell, B. Hamilton, M. Shoemaker, M. Tagliaferri, I. Cohen, and D. Tripathy, "Antiproliferative activity of Chinese medicinal herbs on breast cancer cells in vitro," Anticancer Research, vol. 22, no. 6C, pp. 3843-3852, 2002.

[170] M. Shoemaker, B. Hamilton, S. H. Dairkee, I. Cohen, and M. J. Campbell, "In vitro anticancer activity of twelve Chinese medicinal herbs," Phytotherapy Research, vol. 19, no. 7, pp. 649651, 2005.

[171] S. Fong, M. Shoemaker, J. Cadaoas et al., "Molecular mechanisms underlying selective cytotoxic activity of BZL101, an extract of Scutellaria barbata, towards breast cancer cells," Cancer Biology and Therapy, vol. 7, no. 4, pp. 577-586, 2008.

[172] A. T. Perez, B. Arun, D. Tripathy et al., "A phase 1B dose escalation trial of Scutellaria barbata (BZL101) for patients with metastatic breast cancer," Breast Cancer Research and Treatment, vol. 120, no. 1, pp. 111-118, 2010.

[173] J. Klawitter, J. Klawitter, J. Gurshtein et al., "Bezielle (BZL101)induced oxidative stress damage followed by redistribution of metabolic fluxes in breast cancer cells: a combined proteomic and metabolomic study," International Journal of Cancer, vol. 129, no. 12, pp. 2945-2957, 2011.

[174] B. B. Aggarwal, "Targeting lammation-induced obesity and metabolic diseases by curcumin and other nutraceuticals," Annual Review of Nutrition, vol. 30, pp. 173-199, 2010.

[175] V. P. Menon and A. R. Sudheer, "Antioxidant and antiinflammatory properties of curcumin," Advances in Experimental Medicine and Biology, vol. 595, pp. 105-125, 2007.

[176] A. Goel and B. B. Aggarwal, "Curcumin, the golden spice from Indian saffron, is a chemosensitizer and radiosensitizer for tumors and chemoprotector and radioprotector for normal organs," Nutrition and Cancer, vol. 62, no. 7, pp. 919-930, 2010.

[177] M. Jiang, O. Huang, X. Zhang et al., "Curcumin induces cell death and restores tamoxifen sensitivity in the antiestrogenresistant Breast Cancer Cell Lines MCF-7/LCC2 and MCF7/LCC9," Molecules, vol. 18, no. 1, pp. 701-720, 2013.

[178] M. Bayet-Robert, F. Kwiatkowski, M. Leheurteur et al., "Phase I dose escalation trial of docetaxel plus curcumin in patients with advanced and metastatic breast cancer," Cancer Biology and Therapy, vol. 9, no. 1, 2010.

[179] K. Mehta, P. Pantazis, T. McQueen, and B. B. Aggarwal, "Antiproliferative effect of curcumin (diferuloylmethane) against human breast tumor cell lines," Anti-Cancer Drugs, vol. 8, no. 5, pp. 470-481, 1997.

[180] A. Shehzad, S. Khan, and Y. Sup Lee, "Curcumin molecular targets in obesity and obesity-related cancers," Future Oncology, vol. 8, no. 2, pp. 179-190, 2012.

[181] P. Anand, C. Sundaram, S. Jhurani, A. B. Kunnumakkara, and B. B. Aggarwal, "Curcumin and cancer: an "old-age" disease with an "age-old” solution," Cancer Letters, vol. 267, no. 1, pp. 133-164, 2008.

[182] M. R. C. Schetinger, I. L. G. Farias, M. C. S. Araújo et al., "Uncaria tomentosa for reducing side effects caused by chemotherapy in CRC patients: clinical trial," Evidence-based Complementary and Alternative Medicine, vol. 2012, Article ID 892182, 8 pages, 2012.

[183] Y. Sheng, R. W. Pero, and H. Wagner, "Treatment of chemotherapy-induced leukopenia in a rat model with aqueous extract from Uncaria tomentosa," Phytomedicine, vol. 7, no. 2, pp. 137-143, 2000.

[184] M. Wurm, L. Kacani, G. Laus, K. Keplinger, and M. P. Dierich, "Pentacyclic oxindole alkaloids from Uncaria tomentosa induce human endothelial cells to release a lymphocyte-proliferationregulating factor," Planta Medica, vol. 64, no. 8, pp. 701-704, 1998.

[185] L. Allen-Hall, P. Cano, J. T. Arnason, R. Rojas, O. Lock, and R. M. Lafrenie, "Treatment of THP-1 cells with Uncaria tomentosa extracts differentially regulates the expression if IL- $1 \beta$ and TNF$\alpha$, Journal of Ethnopharmacology, vol. 109, no. 2, pp. 312-317, 2007.

[186] R. Pilarski, H. Zieliński, D. Ciesiołka, and K. Gulewicz, "Antioxidant activity of ethanolic and aqueous extracts of Uncaria tomentosa (Willd.) DC, Journal of Ethnopharmacology, vol. 104, no. 1-2, pp. 18-23, 2006.

[187] L. Riva, D. Coradini, G. Di Fronzo et al., "The antiproliferative effects of Uncaria tomentosa extracts and fractions on the growth of breast cancer cell line," Anticancer Research, vol. 21, no. 4A, pp. 2457-2461, 2001.

[188] L. Huai, M. Broffman, and S. Pei, "A Comprehensive Textbook," in China Acupuncture and Moxibustion Supplies, Taipei, Taiwan, 1976.

[189] Shanghai College of Traditional Medicine, Acupuncture. A Comprehensive Text, Eastland, Seattle, Wash, USA, 1987.

[190] Beijing Shanghai aNCoTCM, Essentials of Chinese Acupuncture, Foreign Language Press, Beijing, China, 1980.

[191] S. Schroeder, G. Meyer-Hamme, J. Zhang, S. Epplée, T. Friedemann, and W. Hu, "An acupuncture research protocol developed from historical writings by mathematical reflections: a rational individualized acupoint selection method for immediate pain relief," Evidence-Based Complementary and Alternative Medicine, vol. 2013, Article ID 256754, 16 pages, 2013. 
[192] A. Ellis, N. Wiseman, and K. Boss, Fundamentals of Chinese Acupuncture, Paradigm, Brookline, Mass, USA, 1991.

[193] J. Zhang, B. X. Zhao, and X. L. Lao, Acupuncture and Moxibustion, People's Medical Publising House, Beijing, China, 2004.

[194] H. Guo, J. Tian, X. Wang, Y. Fang, Y. Hou, and J. Han, "Brain substrates activated by electroacupuncture of different frequencies (I): comparative study on the expression of oncogene c-fos and genes coding for three opioid peptides," Molecular Brain Research, vol. 43, no. 1-2, pp. 157-166, 1996.

[195] J.-H. Lee and A. J. Beitz, “The distrubution of brain-stem and spinal cord nuclei associated with different frequencies of electroacupuncture analgesia," Pain, vol. 52, no. 1, pp. 11-28, 1993.

[196] J. Filshie and J. W. Thompson, "Acupuncture," in The Oxford Textbook of Palliative Medicine, G. Hanks, N. I. Cherny, N. A. Christakis et al., Eds., pp. 772-778, Oxford University Press, 4th edition, 2009.

[197] J. S. Han and L. Terenius, "Neurochemical basis of acupuncture analgesia," Annual Review of Pharmacology and Toxicology, vol. 22, pp. 193-220, 1982.

[198] K. Uvnäs-Moberg, "Physiological and endocrine effects of social contact," Annals of the New York Academy of Sciences, vol. 807, pp. 146-163, 1997.

[199] L. U. Roth, A. Maret-Maric, R. H. Adler, and B. E. Neuenschwander, "Acupuncture points have subjective (needing sensation) and objective (serum cortisol increase) specificity," Acupuncture in Medicine, vol. 15, no. 1, pp. 2-5, 1997.

[200] W. Zhang, Z. Jin, G. Cui et al., "Relations between brain network activation and analgesic effect induced by low vs. high frequency electrical acupoint stimulation in different subjects: a functional magnetic resonance imaging study," Brain Research, vol. 982, no. 2, pp. 168-178, 2003.

[201] J. Pariente, P. White, R. S. J. Frackowiak, and G. Lewith, "Expectancy and belief modulate the neuronal substrates of pain treated by acupuncture," NeuroImage, vol. 25, no. 4, pp. 1161-1167, 2005.

[202] A. White, M. Cummings, and J. Filshie, An Introduction to Western Medical Acupuncture, Churchill Livingstone, 1st edition, 2008.

[203] Y. J. Jeong, Y. S. Park, H. J. Kwon, I. H. Shin, J. G. Bong, and S. H. Park, "Acupuncturefor the treatment of hot flashes in patients with Breast Cancer receiving antiestrogen therapy: a pilot study in Korean women," Journal of Alternative and Complementary Medicine, 2013.

[204] J. Filshie, T. Bolton, D. Browne, and S. Ashley, "Acupuncture and self acupuncture for long term treatment of vasomotor symptoms in cancer patients - Audit and treatment algorithm," Acupuncture in Medicine, vol. 23, no. 4, pp. 171-180, 2005.

[205] J. Filshie and J. Hester, "Guidelines for providing acupuncture treatment for cancer patients - A peer-reviewed sample policy document," Acupuncture in Medicine, vol. 24, no. 4, pp. 172-182, 2006.

[206] J. M. Ezzo, M. A. Richardson, A. Vickers et al., "Acupuncturepoint stimulation for chemotherapy-induced nausea or vomiting," Cochrane Database of Systematic Reviews, no. 2, Article ID CD002285, 2006.

[207] M. H. J. van den Beuken-van Everdingen, J. M. de Rijke, A. G. Kessels, H. C. Schouten, M. van Kleef, and J. Patijn, "Prevalence of pain in patients with cancer: a systematic review of the past 40 years," Annals of Oncology, vol. 18, no. 9, pp. 1437-1449, 2007.
[208] C. A. Paley, M. I. Bennett, and M. I. Johnson, "Acupuncture for cancer-induced bone pain?" Evidence-Based Complementary and Alternative Medicine, vol. 2011, Article ID 671043, 6 pages, 2011.

[209] C. A. Paley, M. I. Johnson, O. A. Tashani, and A. Bagnall, "Acupuncture for cancer pain in adults," Cochrane Database of Systematic Reviews, vol. 1, Article ID CD007753, 2011.

[210] K. D. Crew, J. L. Capodice, H. Greenlee et al., "Pilot study of acupuncture for the treatment of joint symptoms related to adjuvant aromatase inhibitor therapy in postmenopausal breast cancer patients," Journal of Cancer Survivorship, vol. 1, no. 4, pp. 283-291, 2007.

[211] O. Minton, A. Richardson, M. Sharpe, M. Hotopf, and P. Stone, "A systematic review and meta-analysis of the pharmacological treatment of cancer-related fatigue," Journal of the National Cancer Institute, vol. 100, no. 16, pp. 1155-1166, 2008.

[212] A. J. Vickers, D. J. Straus, B. Fearon, and B. R. Cassileth, "Acupuncture for postchemotherapy fatigue: a phase II study," Journal of Clinical Oncology, vol. 22, no. 9, pp. 1731-1735, 2004.

[213] C. Smith, B. Carmady, C. Thornton, J. Perz, and J. M. Ussher, "The effect of acupuncture on post-cancer fatigue and wellbeing for women recovering from breast cancer: a pilot randomised controlled trial," Medical Acupuncture, vol. 31, no. 1, pp. 9-15, 2013.

[214] Molassiotis, J. Bardy, J. Finnegan-John et al., "Acupuncture for cancer-related fatigue in patients with breast cancer: a pragmatic randomized controlled trial," Journal of Clinical Oncology, vol. 30, no. 36, pp. 4470-4476, 2012.

[215] M. F. Johnston, R. D. Hays, S. K. Subramanian et al., "Patient education integrated with acupuncture for relief of cancerrelated fatigue randomized controlled feasibility study," $B M C$ Complementary and Alternative Medicine, vol. 11, article 49, 2011.

[216] A. Molassiotis, P. Sylt, and H. Diggins, "The management of cancer-related fatigue after chemotherapy with acupuncture and acupressure: a randomised controlled trial," Complementary Therapies in Medicine, vol. 15, no. 4, pp. 228-237, 2007.

[217] R. J. Leo and J. S. A. Ligot Jr., "A systematic review of randomized controlled trials of acupuncture in the treatment of depression," Journal of Affective Disorders, vol. 97, no. 1-3, pp. 13-22, 2007.

[218] D. Duan, Y. Tu, L. Chen, and Z. Wu, "Efficacy evaluation for depression with somatic symptoms treated by electroacupuncture combined with fluoxetine," Journal of Traditional Chinese Medicine, vol. 29, no. 3, pp. 167-173, 2009.

[219] E. M. Walker, A. I. Rodriguez, B. Kohn et al., "Acupuncture versus venlafaxine for the management of vasomotor symptoms in patients with hormone receptor-positive breast cancer: a randomized controlled trial," Journal of Clinical Oncology, vol. 28, no. 4, pp. 634-640, 2010.

[220] W. E. Mehling, B. Jacobs, M. Acree et al., "Symptom management with massage and acupuncture in postoperative Cancer patients: a randomized controlled trial," Journal of Pain and Symptom Management, vol. 33, no. 3, pp. 258-266, 2007.

[221] Y. C. Hai, Y. Shi, S. N. Chi, M. C. Sai, K. K. L. Yung, and L. Z. Qing, "Auricular acupuncture treatment for insomnia: a systematic review," Journal of Alternative and Complementary Medicine, vol. 13, no. 6, pp. 669-676, 2007.

[222] D. K. Cheuk, W. F. Yeung, K. F. Chung, and V. Wong, "Acupuncture for insomnia," Cochrane Database of Systematic Reviews, no. 3, Article ID CD005472, 2007.

[223] J. L. Otte, J. S. Carpenter, X. Zhong, and P. A. S. Johnstone, "Feasibility study of acupuncture for reducing sleep disturbances 
and hot flashes in postmenopausal breast cancer survivors," Clinical Nurse Specialist, vol. 25, no. 5, pp. 228-236, 2011.

[224] J. E. Harrington, B. S. Baker, and C. J. Hoffman, "Effect of an integrated support programme on the concerns and wellbeing of women with breast cancer: a national service evaluation," Complementary Therapies in Clinical Practice, vol. 18, no. 1, pp. 10-15, 2012.

[225] J. Frisk, A. Källström, N. Wall, M. Fredrikson, and M. Hammar, "Acupuncture improves health-related quality-of-life (HRQoL) and sleep in women with breast cancer and hot flushes," Supportive Care in Cancer, pp. 1-10, 2011.

[226] J. Hervik and O. Mjåland, "Quality of life of breast cancer patients medicated with anti-estrogens, 2 years after acupuncture treatment: a qualitative study," International Journal of Women's Health, vol. 2, no. 1, pp. 319-325, 2010.

[227] E. Dean-Clower, A. M. Doherty-Gilman, A. Keshaviah et al., "Acupuncture as palliative therapy for physical symptoms and quality of life for advanced cancer patients," Integrative Cancer Therapies, vol. 9, no. 2, pp. 158-167, 2010.

[228] W. Lu, D. Hu, E. Dean-Clower et al., "Acupuncture for chemotherapy-induced leukopenia: exploratory meta-analysis of randomized controlled trials," Journal of the Society for Integrative Oncology, vol. 5, no. 1, pp. 1-10, 2007.

[229] A. White, "A cumulative review of the range and incidence of significant adverse events associated with acupuncture," Acupuncture in Medicine, vol. 22, no. 3, pp. 122-133, 2004.

[230] G. Ernst, H. Strzyz, and H. Hagmeister, "Incidence of adverse effects during acupuncture therapy-a multicentre survey," Complementary Therapies in Medicine, vol. 11, no. 2, pp. 93-97, 2003.

[231] A. White, S. Hayhoe, A. Hart, and E. Ernst, "Adverse events following acupuncture: prospective survey of 32000 consultations with doctors and physiotherapists," British Medical Journal, vol. 323, no. 7311, pp. 485-486, 2001.

[232] D. Melchart, W. Weidenhammer, A. Streng et al., "Prospective investigation of adverse effects of acupuncture in 97733 patients," Archives of Internal Medicine, vol. 164, no. 1, pp. 104105,2004

[233] A. Vickers and C. Zollman, "ABC of complementary medicine: acupuncture," British Medical Journal, vol. 319, no. 7215, pp. 973976, 1999.

[234] S. M. Sagar, "Acupuncture as an evidence-based option for symptom control in cancer patients," Current Treatment Options in Oncology, vol. 9, no. 2-3, pp. 117-126, 2008.

[235] C. M. Witt, D. Pach, B. Brinkhaus et al., "Safety of acupuncture: results of a prospective observational study with 229,230 patients and introduction of a medical information and consent form," Forschende Komplementarmedizin, vol. 16, no. 2, pp. 9197, 2009.

[236] W. Lu, E. Dean-Clower, A. Doherty-Gilman, and D. S. Rosenthal, "The value of acupuncture in Cancer care," Hematology/Oncology Clinics of North America, vol. 22, no. 4, pp. 631648, 2008.

[237] E. Tukmachi, "Treatment of hot flushes in breast cancer patients with acupuncture," Acupuncture in Medicine, vol. 18, no. 1, pp. 22-27, 2000.

[238] W. Lu and D. S. Rosenthal, "Recent advances in oncology acupuncture and safety considerations in practice," Current Treatment Options in Oncology, vol. 11, no. 3-4, pp. 141-146, 2010. 


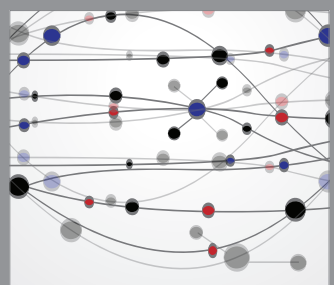

The Scientific World Journal
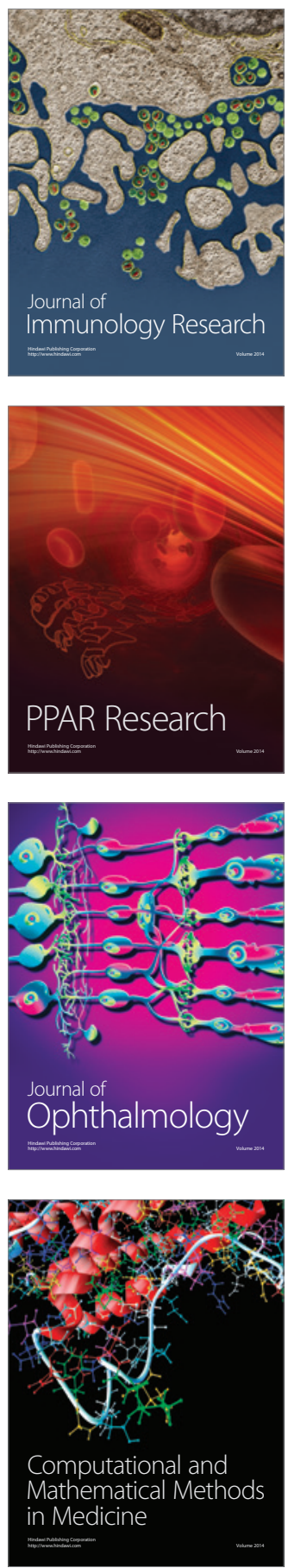

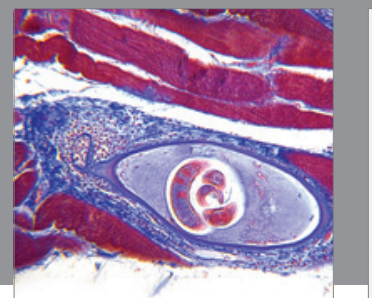

Gastroenterology

Research and Practice
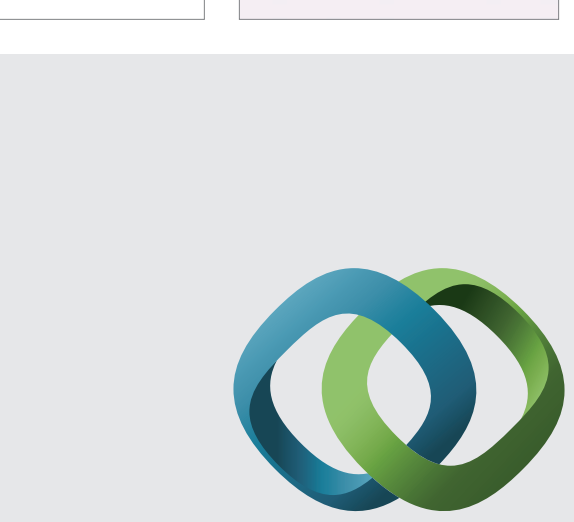

\section{Hindawi}

Submit your manuscripts at

http://www.hindawi.com
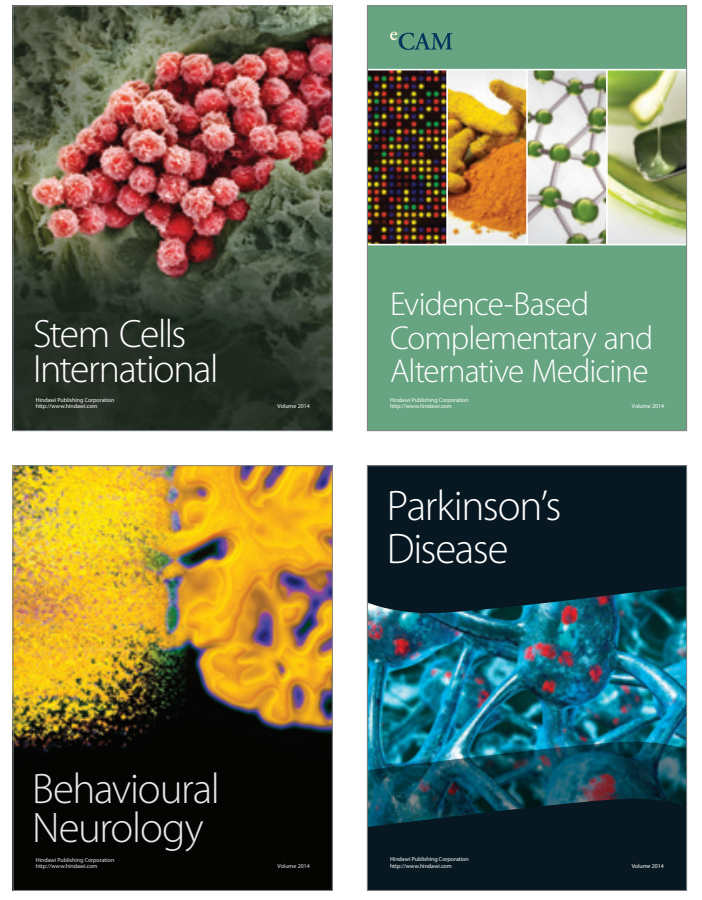
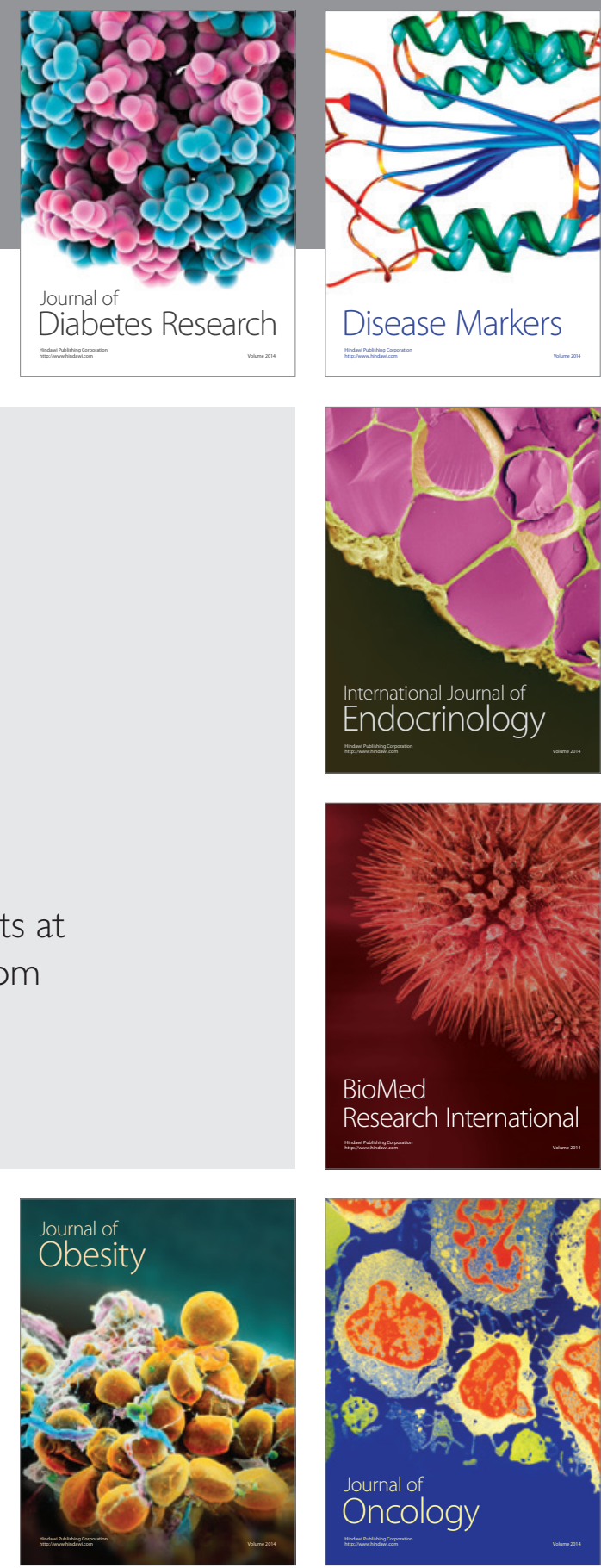

Disease Markers
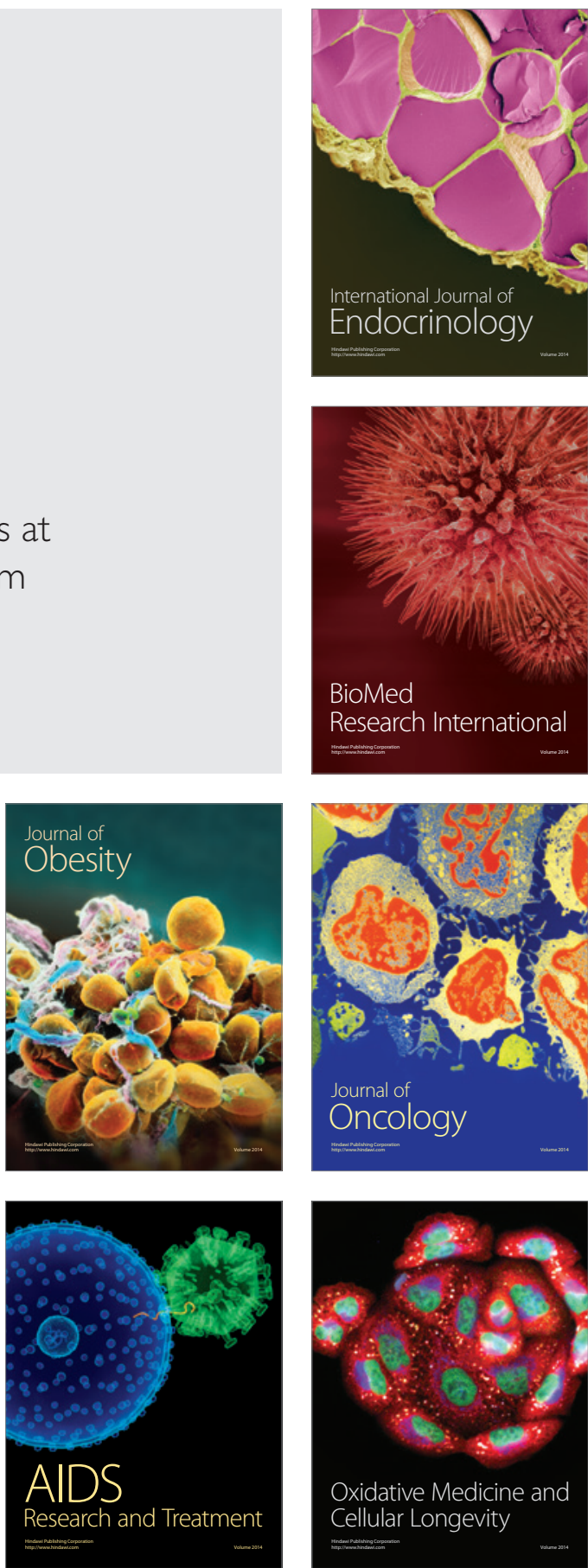